National Highuay Traffic Safety Admint
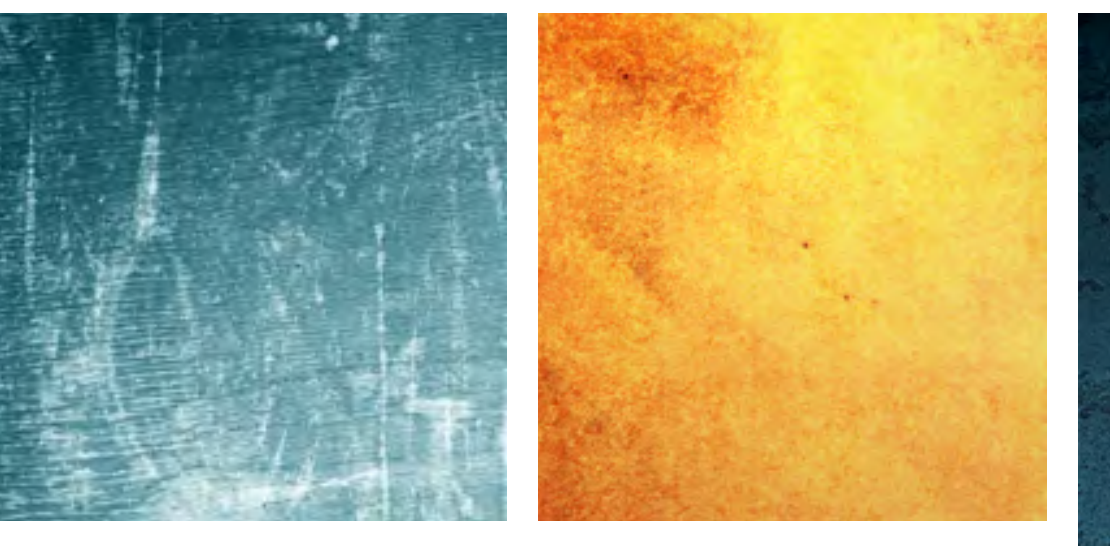

\title{
Field and Simulator Evaluations of a PB-Based Attention Maintenance Training Program
}

\section{2}


This publication is distributed by the U.S. Department of Transportation, National Highway Traffic Safety Administration, in the interest of information exchange. The opinions, findings, and conclusions expressed in this publication are those of the authors and not necessarily those of the Department of Transportation or the National Highway Traffic Safety Administration. The United States Government assumes no liability for its contents or use thereof. If trade or manufacturers' names or products are mentioned, it is because they are considered essential to the object of the publication and should not be construed as an endorsement. The United States Government does not endorse products or manufacturers. 
Technical Report Documentation Page

\begin{tabular}{|c|c|c|c|c|c|c|}
\hline \multicolumn{2}{|l|}{$\begin{array}{l}\text { 1. Report No. } \\
\text { DOT HS } 811469\end{array}$} & \multicolumn{2}{|c|}{ 2. Government Accession No. } & \multicolumn{3}{|c|}{ 3. Recipient's Catalog No. } \\
\hline \multirow{2}{*}{\multicolumn{4}{|c|}{$\begin{array}{l}\text { 4. Title and Subject } \\
\text { Field and Simulator Evaluations of a PC-based Attention Maintenance } \\
\text { Training Program }\end{array}$}} & \multicolumn{3}{|c|}{$\begin{array}{l}\text { 5. Report Date } \\
\text { July } 2011 \\
\end{array}$} \\
\hline & & & & \multicolumn{3}{|c|}{$\begin{array}{l}\text { 6. Performing Organization Code } \\
211.9\end{array}$} \\
\hline \multicolumn{4}{|c|}{$\begin{array}{l}\text { 7. Authors } \\
\text { F. Dennis Thomas, III, Sandy Pollatsek*, Anuj Pradhan*, Gautam } \\
\text { Divekar*, Richard D. Blomberg, Ian Reagan^, and Donald Fisher* }\end{array}$} & \multicolumn{3}{|c|}{$\begin{array}{l}\text { 8. Performing Organization Report No. } \\
211.9-1\end{array}$} \\
\hline \multirow{2}{*}{\multicolumn{4}{|c|}{$\begin{array}{l}\text { 9. Performing Organization Name and Address } \\
\text { Dunlap and Associates, Inc. } \\
110 \text { Lenox Avenue } \\
\text { Stamford, CT } 06906\end{array}$}} & \multicolumn{3}{|c|}{ 10. Work Unit No. (TRAIS) } \\
\hline & & & & \multicolumn{3}{|c|}{$\begin{array}{l}\text { 11. Contract or Grant No. } \\
\text { DTNH22-05-D-35043, Task Order } 9\end{array}$} \\
\hline \multicolumn{4}{|c|}{$\begin{array}{l}\text { 12. Sponsoring Agency Name and Address } \\
\text { National Highway Traffic Safety Administration } \\
1200 \text { New Jersey Avenue SE. } \\
\text { Washington, DC } 20590\end{array}$} & \multicolumn{3}{|c|}{ 14. Sponsoring Agency Code } \\
\hline \multicolumn{7}{|c|}{$\begin{array}{l}\text { 15. Supplementary Notes } \\
\text { *University of Massachusetts Amherst. ^Ian Reagar }\end{array}$} \\
\hline \multicolumn{7}{|c|}{ 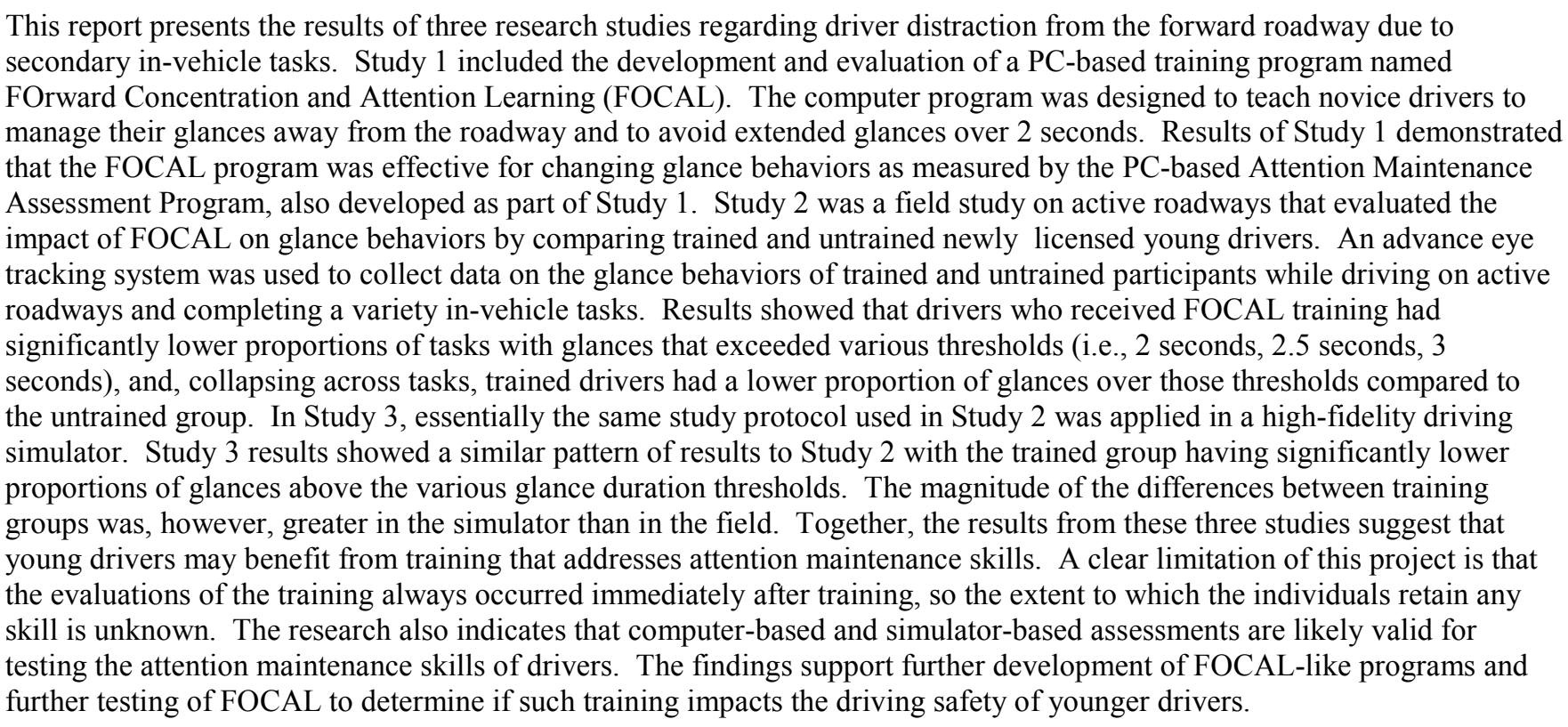 } \\
\hline $\begin{array}{l}\text { 17. Key Words } \\
\text { Attention Maintenance } \\
\text { Young Drivers } \\
\text { Field Drive }\end{array}$ & $\begin{array}{l}\text { Driver Dis } \\
\text { Training } \\
\text { Simulator }\end{array}$ & tion & $\begin{array}{l}\text { 18. Distributi } \\
\text { This report is } \\
\text { Technical Info }\end{array}$ & & $\begin{array}{l}\text { the public from th } \\
\text { ervice at www.ntis. }\end{array}$ & tional \\
\hline $\begin{array}{l}\text { 19. Security Classif. (o } \\
\text { Unclassified }\end{array}$ & his report) & & lassif. (of this $\mathrm{p}$ & & $\begin{array}{c}\text { 21. No. of Pages } \\
72\end{array}$ & 22. Price \\
\hline
\end{tabular}

Form DOT F 1700.7 (8-72) 


\section{ACKNOWLEDGEMENTS}

The authors recognize the efforts of the students and staff of the Human Performance Laboratory at the University of Massachusetts Amherst who assisted with data collection, coding, and analysis.

The authors thank the administrators at Millburn High School, Dan Brundage, the participating Millburn High School students, and the Don-Tre Driving School for their efforts during the field study. Without their cooperation and assistance a field study of this magnitude could not have been easily accomplished. 


\section{EXECUTIVE SUMMARY}

\section{Introduction}

Evidence on the road (Wikman, Nieminen, \& Summala, 1998) and in a driving simulator (Chan, Pradhan, Knodler, Pollatsek, \& Fisher, 2008) suggests that when conducting nondriving related in-vehicle tasks, teen drivers are much more likely to glance inside the vehicle for long periods of time than are more experienced drivers. In a naturalistic field study, such periods of distraction were shown to be highly related to crashes and near crashes for drivers of all ages, but especially for teen drivers (Klauer, Dingus, Neale, Sudweeks, \& Ramsey, 2006). Simply training drivers never to glance inside the vehicle, however, could be unsafe since glances at gauges and mirrors might actually serve to decrease crash risk. Also, given the numerous and increasing sources of distraction in modern vehicles (e.g., radio/entertainment systems, cellular phones), it would be naive to think that drivers will voluntarily ignore the temptation to look away from the forward roadway while they are driving. This supports the potential benefit of a training program that can help novice drivers learn how to distribute more safely the time that they spend on in-vehicle tasks.

This report describes the methods and results of three coordinated studies related to the development of a PC-based attention maintenance training program and its evaluation on a computer, in the field, and in a high-fidelity driving simulator. Study 1 developed and evaluated the training program on a PC. Study 2 compared the performance of a trained group of young novice drivers to that of a similar group of untrained young drivers when driving on the road in traffic. Study 3 repeated the protocol of Study 2 in a driving simulator. All three evaluations of the training program occurred immediately after training.

\section{Study 1}

In Study 1, the PC-based The FOrward Concentration and Attention Learning (FOCAL) program was created to teach novice drivers how to reduce their glance durations to less than 2 seconds while still performing an in-vehicle task accurately. In order to assess performance on FOCAL, the Attention Maintenance Assessment Program (AMAP) was also developed. This assessment program used an innovative approach to determine when drivers glanced away from the simulated roadway on the computer screen. The computer screen was split in half horizontally to display the tasks. The task displayed at the top of the screen was to search a video recording of a drive down a local roadway and identify vehicles, pedestrians and bicyclists that posed a threat. The other task displayed on the bottom half of the computer screen required drivers to determine if a set of streets was on a map. Only one task, however, could be viewed at a time. This required the participants to toggle back and forth between the tasks to successfully complete each. Participants were told that they needed to identify as many potential threats in the video as possible while also determining if the streets of interest were actually on the map. Once the scenario began, the video played continuously, but when the map task was initiated by the participant, the map view replaced the video view while the video played in real time in the background. Therefore, any time the participant toggled to the map view, the video was out of sight but potential hazards might still be materializing. The program recorded the frequency and duration that participants viewed each task. 
Fifteen participants were randomly assigned to FOCAL training and 15 to placebo training. The placebo training program took about the same amount of time to complete as FOCAL. Participants in the placebo training group were given printed instruction on the meaning of road signs, signals and pavement markings.

As a pre-test, each experimental participant first completed the AMAP program to get a baseline measure of willingness to look away from the roadway and to provide feedback during the training. After completing AMAP, participants taking FOCAL training saw the following sequence of events: (1) a video that went blank whenever the participant looked away from the roadway in the assessment test he or she just completed; (2) a video that went blank whenever the participant looked away from the roadway during the baseline test, and for glances greater than 2 seconds, a timer appeared on the screen to show participants just how long their glances were; (3) a sequence of videos that displayed the map for 3 seconds whenever the participant wanted to see the map, after which the display automatically returned to the video view; (4) a sequence of videos that displayed the map for 3 seconds, followed by a loud tone if the map remained on for more than 3 seconds; (5) similar sequences displayed for 2 seconds. After training, the AMAP was again administered to all of the participants.

An analysis of the percentage of glances to the map task greater than $x$ seconds $\quad(x=0$, $0.5,1.0,1.5, \ldots, 8.0 \mathrm{~s}$ ) during pre-training indicated that the FOCAL and placebo groups' glance durations did not differ significantly. For the post-training test, the participants trained with FOCAL (Figure ES-1) showed statistically significant reductions in the percentage of glances greater than $x$ seconds compared to participants trained with the placebo program. Moreover, the distribution of glances did not change for the placebo group before and after training. 
Figure ES-1. Distribution of Glance Durations Before and After Focal Training

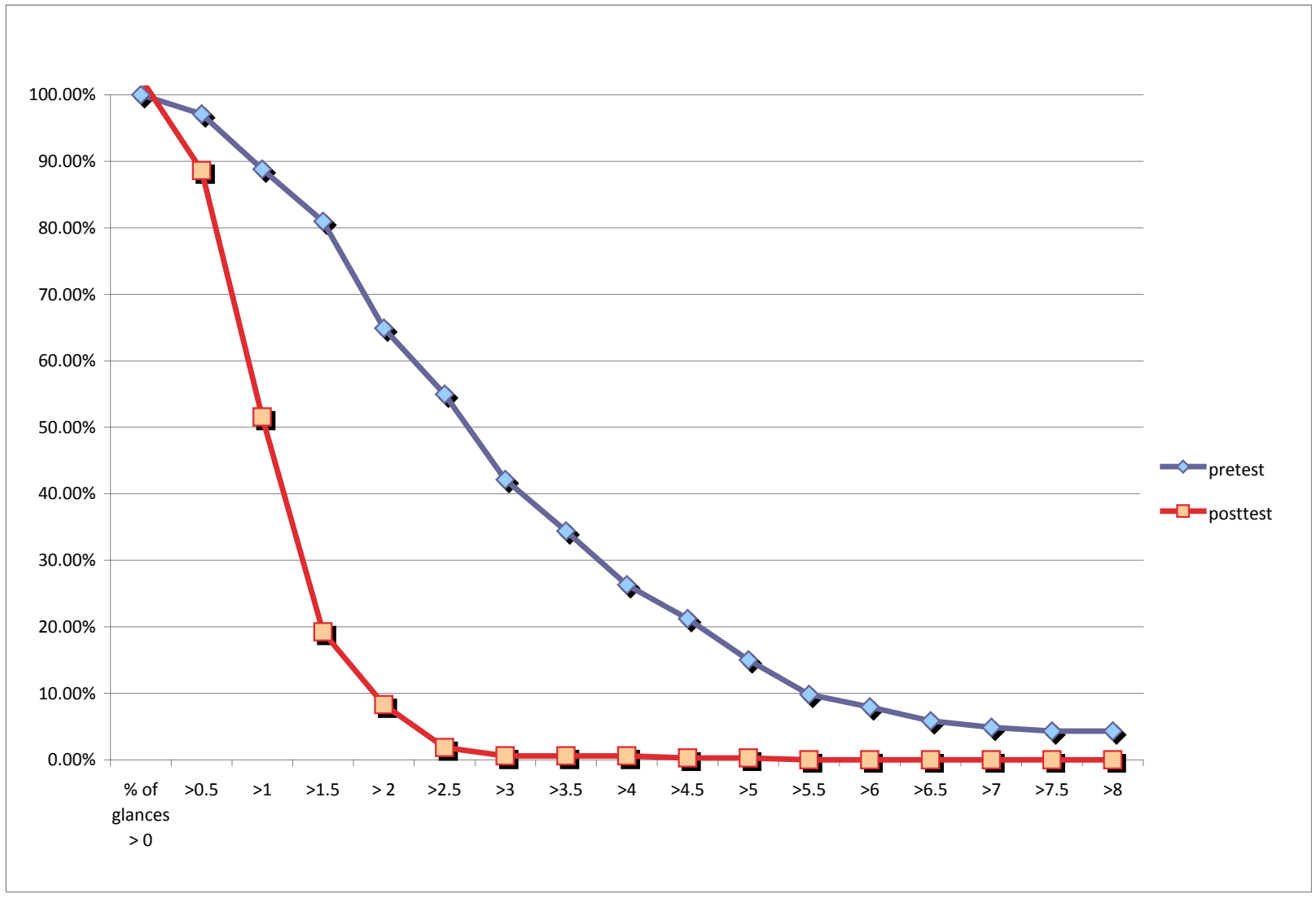

\section{Study 2}

In this study, newly licensed drivers completed a field drive on active roadways immediately after receiving FOCAL or placebo training. Participants were recruited from Millburn High School in Millburn, New Jersey. Students could only participate if they had a learner's permit and at least 5 hours of driving experience, or had held a restricted driver's license for less than 6 months. Each participant drove the same route beginning and ending at the school in a dual brake car. A certified driving instructor sat in the front seat to control the drive and monitor safety. A researcher in the back seat prompted the drivers to start the secondary tasks and recorded data about their performance.

The secondary tasks participants completed while driving included three vehicle/driving tasks and six nondriving tasks. The vehicle/driving tasks included turning the headlights on high beam, activating the front window defroster, and activating the emergency flashers. The nonvehicle tasks included tuning the radio, looking for a $\mathrm{CD}$ in a case, trying to find a street on a map, and taking 40 cents out of a cup holder. In one instance the $\mathrm{CD}$ was present and in the other it was not. Similarly, in one map task the street was present and in the other it was not. For the change task, 10 coins where placed in the cup holder, but only one combination of coins added up to 40 cents ( 1 quarter, 1 dime, 1 nickel). 
A portable, lightweight eye tracker (Mobile Eye developed by Applied Science Laboratories) was used to collect the eye-movement data for each driver. It had a lightweight optical system consisting of an eye camera and a color scene camera mounted on a pair of safety goggles. The images from these two cameras were interleaved and recorded on a remote recording system, thus ensuring no loss of resolution. The interleaved video was then transferred to a PC where the images were separated and processed. Viable eye tracker data from the field drives were obtained for 37 participants. A total of 19 (10 males, 9 females) completed the FOCAL training, and 18 (11 males, 7 females) completed the placebo training.

Analyses of the eye tracker data showed that there were different eye-glance behaviors between the vehicle/driving tasks and nondriving tasks. As such, analyses comparing the FOCAL and placebo trained groups were performed separately for these groups of tasks and for all tasks combined. For the nondriving tasks, Table ES-1 shows that the FOCAL training produced a statistically significant effect for three of the four measures reported. The average maximum glance across tasks was over a half a second longer for the placebo training group than for the FOCAL-trained group. The FOCAL trained group also had a significantly lower proportion of tasks with glances that were greater than the 2.0 and $2.5 \mathrm{~s}$ thresholds.

Table ES-1. Nondriving Tasks: Maximum Glance; Percentage of Tasks in Which Maximum Glances Are Over 2.0 s, $2.5 \mathrm{~s}$, and $3.0 \mathrm{~s}$

\begin{tabular}{|c|c|c|c|c|}
\hline \multirow{2}{*}{ Group } & $\begin{array}{c}\text { Max } \\
\text { Glance } \\
\text { (seconds) }\end{array}$ & \multicolumn{3}{|c|}{$\begin{array}{c}\text { Percent of Tasks in Which } \\
\text { Maximum Glance Was } \\
\text { Greater Than }\end{array}$} \\
\cline { 3 - 5 } & & $2 \mathrm{sec}$ & $2.5 \mathrm{sec}$ & $3 \mathrm{sec}$ \\
\hline FOCAL & 2.53 & $59.5 \%$ & $41.9 \%$ & $30.2 \%$ \\
\hline Placebo & 3.07 & $75.9 \%$ & $60.2 \%$ & $41.7 \%$ \\
\hline Placebo - Focal & 0.54 & $16.5 \%$ & $18.3 \%$ & $11.5 \%$ \\
\hline t(35) & 2.358 & 2.279 & 2.267 & 1.456 \\
\hline$p$ & 0.024 & 0.029 & 0.030 & 0.154 \\
\hline
\end{tabular}

Overall, Study 2 demonstrated that the FOCAL-trained participants were significantly less likely than a placebo training group to take excessively long glances away from the roadway when nondriving tasks were performed while on the road in actual traffic.

\section{Study 3}

Study 3 used essentially the same methods as Study 2 except that the drive was completed in a high-fidelity simulator. Participants were recruited from Amherst, Massachusetts, and surrounding towns close to the University of Massachusetts Amherst. There were 40 participants in the experiment, 23 males and 17 females, ranging in age from 16 to 18 . All participants held junior operators' licenses (restricted licenses) for less than 6 months. Twenty participants each were randomly assigned to either the FOCAL or placebo training 
groups. Participants completed the simulator drives immediately after completing the assigned training.

The same secondary tasks from Study 2 were used. As with the field study, analyses examined the vehicle/driving and nondriving tasks separately and combined, although the differences among the two classes of tasks were not as large as those found in the field study. For the six nondriving tasks, Table ES-2 shows that the FOCAL training produced a statistically significant effect for all four measures reported. The average maximum glance across tasks was more than a half second longer for the placebo training group than for the FOCAL-trained group. The percentage of tasks with a glance over the 2.0 -second and 2.5 -second thresholds was significantly less than the percentages for the placebo trained group. The difference between the groups at the 3.0-second threshold approached statistical significance $(p=0.050)$.

Table ES-2. Nondriving Tasks: Maximum Glance; Percentage of Tasks in Which Maximum Glances Are Over 2.0 s, $2.5 \mathrm{~s}$, and 3.0 s

\begin{tabular}{|c|c|c|c|c|}
\hline \multirow{2}{*}{ Group } & \multirow{2}{*}{$\begin{array}{c}\text { Max } \\
\text { Glance } \\
\text { (seconds) }\end{array}$} & \multicolumn{3}{|c|}{$\begin{array}{c}\text { Percent of Tasks in Which } \\
\text { Maximum Glance Was } \\
\text { Greater Than }\end{array}$} \\
\cline { 3 - 5 } & & $2 \mathrm{sec}$ & $2.5 \mathrm{sec}$ & $3 \mathrm{sec}$ \\
\hline FOCAL & 2.486 & $59.2 \%$ & $38.3 \%$ & $21.7 \%$ \\
\hline Placebo & 3.073 & $80.8 \%$ & $67.5 \%$ & $40.8 \%$ \\
\hline Placebo- Focal & 0.587 & $21.7 \%$ & $29.2 \%$ & $19.2 \%$ \\
\hline$t(38)$ & 2.366 & 2.679 & 3.207 & 2.02 \\
\hline$p$ & 0.023 & 0.011 & 0.003 & 0.050 \\
\hline
\end{tabular}

The effect of FOCAL training on the percentage of vehicle/driving tasks in which drivers looked away at least once for more than 2.0, 2.5, and 3.0 seconds was directionally similar to the effects for the nondriving tasks, and the differences among the training groups were statistically significant $(p s<0.05)$ for all four measures (Table ES-3). 
Table ES-3. Vehicle/Driving Tasks: Maximum Glance; Percentage of Tasks in Which Maximum Glances Are Over 2.0 s, $2.5 \mathrm{~s}$, and 3.0 s

\begin{tabular}{|c|c|c|c|c|}
\hline \multirow[b]{2}{*}{ Group } & \multirow{2}{*}{$\begin{array}{c}\text { Max } \\
\text { Glance } \\
\text { (seconds) }\end{array}$} & \multicolumn{3}{|c|}{$\begin{array}{c}\text { Percent of Tasks in Which } \\
\text { Maximum Glance Was } \\
\text { Greater Than }\end{array}$} \\
\hline & & $2.0 \mathrm{sec}$ & $2.5 \mathrm{sec}$ & $3.0 \mathrm{sec}$ \\
\hline FOCAL & 2.206 & $41.7 \%$ & $26.7 \%$ & $18.3 \%$ \\
\hline Placebo & 2.895 & $65.0 \%$ & $61.7 \%$ & $41.7 \%$ \\
\hline Placebo - Focal & 0.689 & $23.3 \%$ & $23.3 \%$ & $23.3 \%$ \\
\hline$t(38)$ & 2.418 & 2.999 & 4.200 & 2.746 \\
\hline p & 0.021 & 0.005 & 0.000 & 0.009 \\
\hline
\end{tabular}

\section{Discussion}

This series of three studies sought to develop and test a PC-based training countermeasure that would reduce inattention to the forward roadway among young, newly licensed drivers. Together, the results from these studies strongly suggest that young drivers could benefit from PC-based training that addresses attention maintenance skills. The major remaining unknown is how long the training effects persist and whether the changes in behavior observed after training are, in fact, associated with reduced crash risk. Specifically, there were three evaluations - one using a PC, one using a simulator, and one field evaluation on open roads -, and each occurred immediately after the training was administered. This research also suggests that computer-based and simulator-based assessments to determine if training has changed forward attention behavior are likely valid, at least for predicting the existence and nature of change if not its absolute magnitude. It therefore follows that further development and evaluation of FOCAL-like programs using techniques similar to the ones employed in these three studies could be beneficial. Since the current studies evaluated the immediate effects of training, a productive next step would be to examine how long such training effects persist. Future research might also assess the extent to which drivers with differing levels of driving experience (e.g., intermediate, older drivers) would benefit from similarly focused training. Ultimately, research might productively examine whether countermeasures such as FOCAL impact the driving safety of younger drivers and the trained drivers throughout their driving careers. 


\section{TABLE OF CONTENTS}

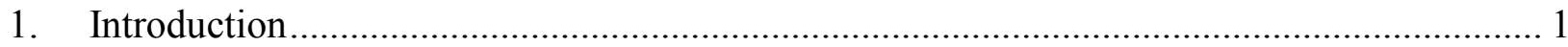

2. Study 1: FOCAL Development and Computer-Based Evaluation ......................................... 3

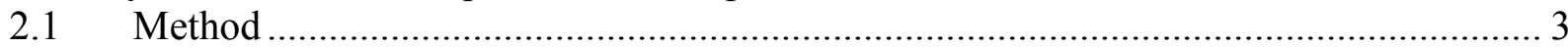

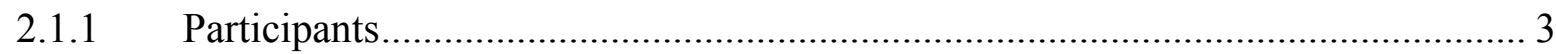

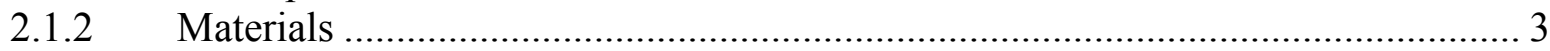

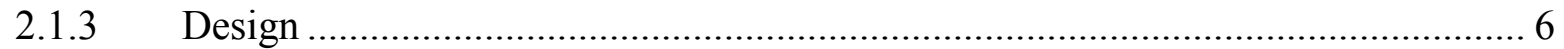

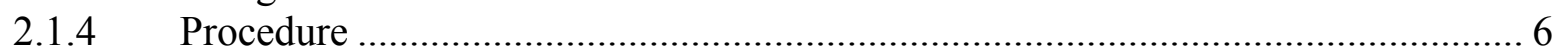

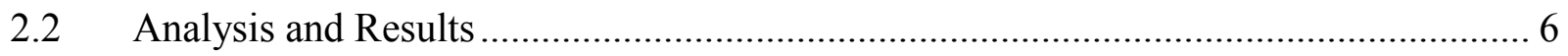

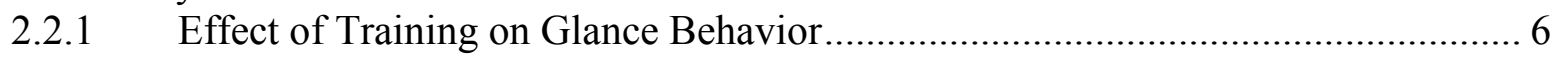

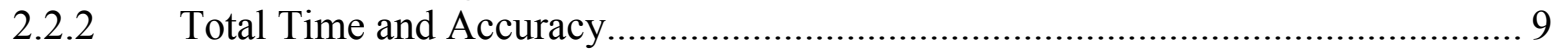

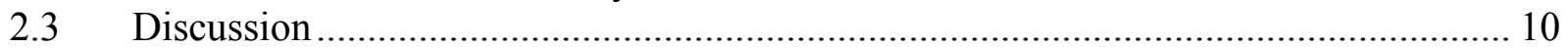

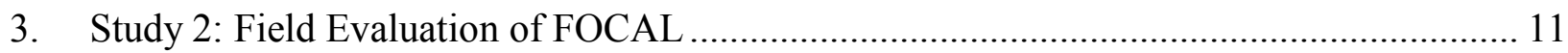

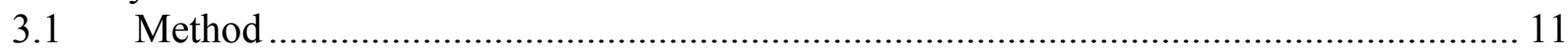

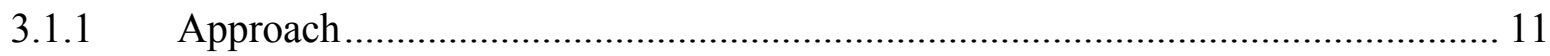

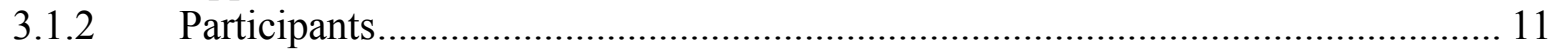

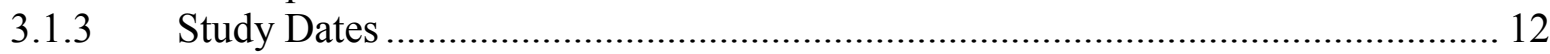

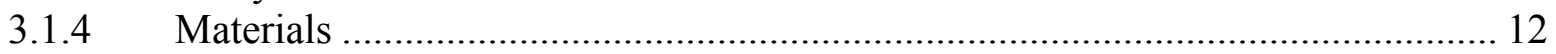

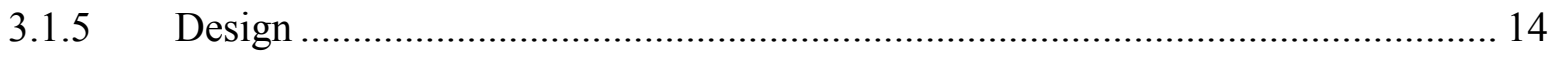

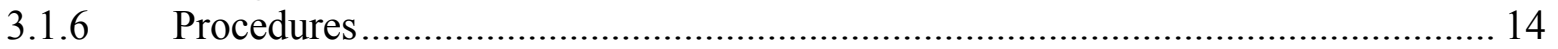

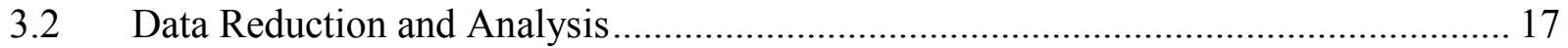

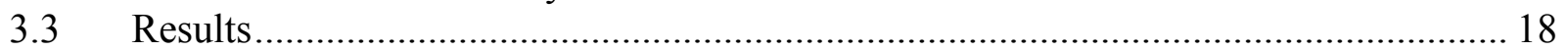

3.3.1 In-Vehicle Glances: Analysis of Differences Among Task Types ....................... 18

3.3.2 In-Vehicle Glances: Analysis of Effects of Training............................................ 19

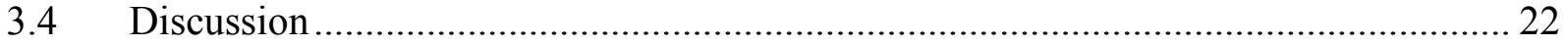

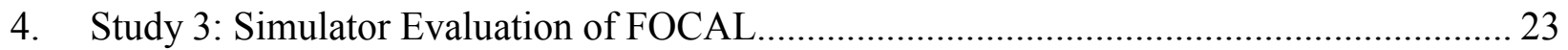

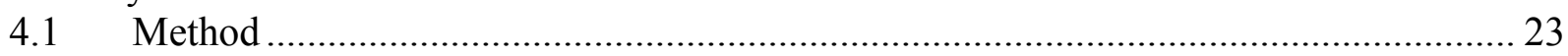

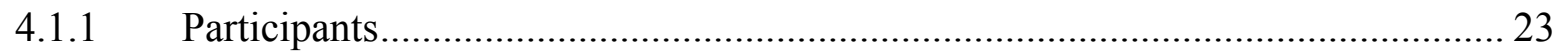

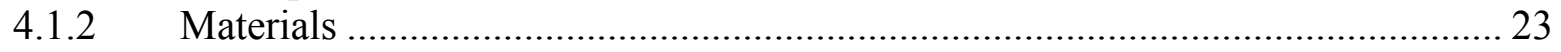

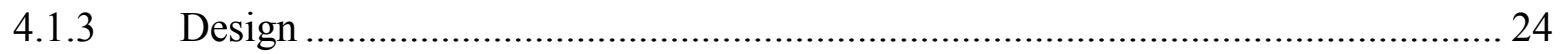

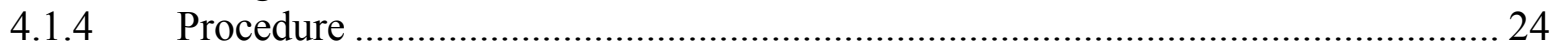

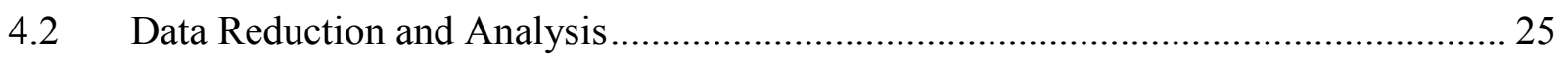

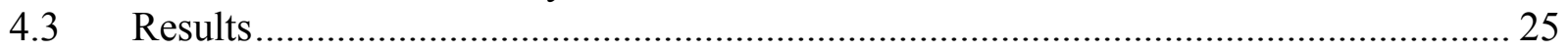

4.3.1 In-Vehicle Glances: Analysis of Differences Among Task Types ........................ 25

4.3.2 In-Vehicle Glances: Analysis of Effects of Training.......................................... 26

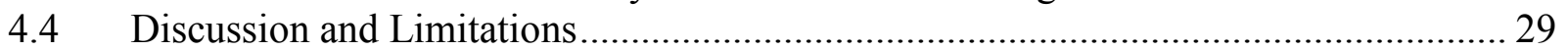

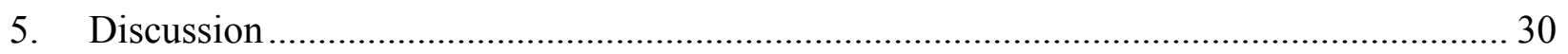

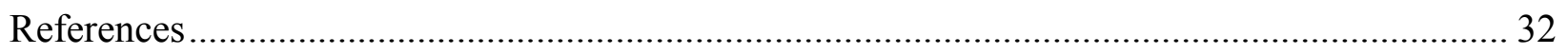

Appendix A: Contents of FOCAL Training and Selected Screenshots ...................................... 34

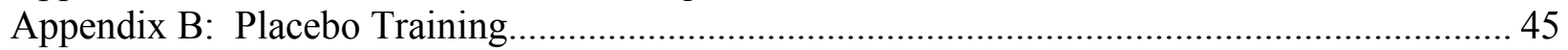




\section{LIST OF TABLES}

Table 1. Comparison of FOCAL Training Group's Pre/Post Differences on AMAP ............. 8

Table 2. Comparison of Post-Test Placebo and Post-Test FOCAL AMAP Scores................. 9

Table 3. Total Time Spent on the Map Task................................................................ 10

Table 4. Total Time, Maximum Glance, and Ratio of Total Time to Maximum Glance for FOCAL and Placebo Groups For Each Task...................................................... 18

Table 5. Nondriving Tasks: Maximum Glance; Percentage of Tasks in Which Maximum Glances Over 2.0 s, 2.5 s, and $3.0 \mathrm{~s}$.............................................................. 19

Table 6. Nondriving Tasks: Percentage of Glances Over $2.0 \mathrm{~s}, 2.5 \mathrm{~s}$, and $3.0 \mathrm{~s}$................. 20

Table 7. Vehicle/Driving Tasks: Maximum Glance; Percentage of Tasks in Which Maximum

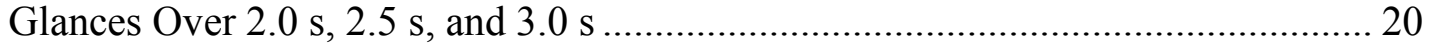

Table 8. Vehicle/Driving Tasks: Percentage of Glances Over $2.0 \mathrm{~s}, 2.5 \mathrm{~s}$, and $3.0 \mathrm{~s} \ldots \ldots \ldots \ldots .21$

Table 9. All Tasks Combined: Maximum Glance; Percentage of Tasks in Which Maximum Glances Over 2.0 s, 2.5 s, and $3.0 \mathrm{~s}$.............................................................. 21

Table 10. All Tasks Combined: Percentage of Glances Over 2.0 s, $2.5 \mathrm{~s}$, and $3.0 \mathrm{~s} \ldots \ldots \ldots \ldots . . .22$

Table 11. Total Time, Maximum Glance, and Ratio of Total Time to Maximum Glance for FOCAL and Placebo Groups For Each Task......................................................... 26

Table 12. Nondriving Tasks: Maximum Glance; Percentage of Tasks in Which Maximum

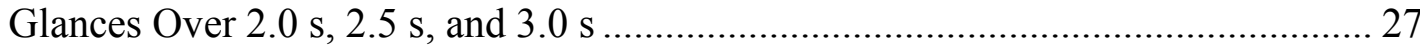

Table 13. Nondriving Tasks: Percent of Glances Over $2.0 \mathrm{~s}, 2.5 \mathrm{~s}$, and $3.0 \mathrm{~s}$...................... 27

Table 14. Vehicle/Driving Tasks: Maximum Glance; Percentage of Tasks in Which Maximum

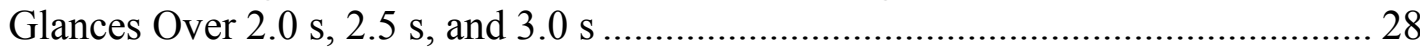

Table 15. Vehicle/Driving Tasks: Percent of Glances Over $2.0 \mathrm{~s}, 2.5 \mathrm{~s}$, and $3.0 \mathrm{~s} . \ldots \ldots \ldots \ldots \ldots . . . . . .28$

Table 16. All Tasks Combined: Maximum Glance; Percentage of Tasks in Which Maximum

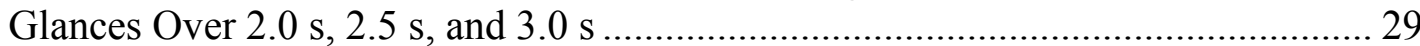

Table 17. All Tasks Combined: Percent of Glances Over 2.0 s, 2.5 s, and 3.0 s................... 29 


\section{LIST OF FIGURES}

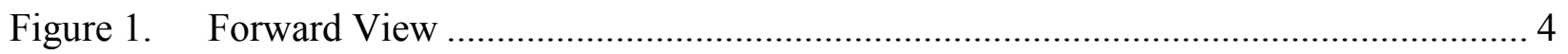

Figure 2. Map View........................................................................................ 5

Figure 3. Distribution of Glance Durations on AMAP Before and After Placebo Training...... 7

Figure 4. Distribution of Glance Durations on AMAP Before and After Focal Training ........ 8

Figure 5. Area in Which Drive Took Place................................................................... 14

Figure 6. Secondary Task Sequence Controlled by Experimenter....................................... 15 


\section{INTRODUCTION}

This is the final report of a research project conducted by Dunlap and Associates, Inc., and the Human Performance Laboratory (HPL) of the University of Massachusetts Amherst (UMass) under Task Order 0009 of contract DTNH22-05-D-35043 from the National Highway Traffic Safety Administration. The project consisted of three coordinated research studies examining various aspects of distracted driving among newly licensed teenage drivers.

Recent crash statistics published by the Department of Transportation for 2008 indicated that inattention or distraction played a causal role in crashes in which nearly 6,000 people died and more than half a million people were injured (Department of Transportation, 2009). These figures are not surprising given the increased use of mobile communication and in-vehicle technologies that require or entice a driver to glance away from the forward roadway (Lerner \& Boyd, 2004; Strayer, Drews, \& Crouch, 2003). The distracted driving problem is also likely to increase because of the emergence of digital billboards and other signage that introduce further visual clutter to the driving environment. (Beijer, Smiley, \& Eizenman, 2004; Smiley, Smahel, \& Eizenman, 2004; Wallace, 2003).

A study conducted by the Virginia Tech Transportation Institute estimated that $78 \%$ of all crashes and $65 \%$ of all near crashes observed in the study involved an inattentive or distracted driver (Klauer, Dingus, Neale, Sudweeks, \& Ramsey, 2006). As such, this problem has received increased attention from the media, the Federal Government, and the research community (e.g., Regan, Lee, \&Young, 2009; Horrey \& Wickens 2007, Chan et al., 2008).

Distraction is especially problematic for younger novice drivers, as evidenced by their elevated crash risk relative to experienced drivers (McKnight \& McKnight, 2003; Wang, Knipling, \& Goodman, 1996; Lerner \& Boyd, 2004; Klauer et al., 2006; Lee, Olsen, \& SimonsMorton, 2006; Chan et al., 2008; Braitman et al., 2008). For example, Klauer et al. (2006) estimated from their naturalistic study that inattention to the roadway was four times more likely to be a contributing factor in crashes and near-crash events for younger drivers (age 18 to 20 years) compared to experienced drivers (35 and older).

Irrespective of the underlying causes of distraction, driver willingness to look away from the forward roadway for long durations while performing in-vehicle tasks is one behavioral attribute that is relatively easy to quantify and is a powerful predictor of crash involvement. (Klauer et al., 2006). Studies in the field (Wikman et al., 1998) and in a simulator (Chan et. al., 2008) confirmed that novice drivers are more likely to take long glances away from the forward roadway compared to older, more experienced drivers. Specifically, Wikman et al. (1998) found that $46 \%$ of inexperienced drivers (mean age 19) took at least once glance over 2.5 seconds inside the vehicle compared to $13 \%$ of the experienced drivers (mean age 36). Also, $29 \%$ of inexperienced drivers took glances of more than 3.0 seconds inside the vehicle compared to $0.0 \%$ of experienced drivers.

Chan et al. (2008) found a similar pattern of results in a high-fidelity driving simulator, although the reported measures were different than those used by Wikman et al. (1998). 
Specifically, the analyses in Wikman et al. focused on the percentage of drivers in each group that had at least one glance that was $2.5 \mathrm{~s}$ or greater. The Chan et al. (2008) analysis was of the percentage of tasks that were longer than a certain time threshold. In the latter study, inexperienced (mean age 16.8 years) drivers performing in-vehicle tasks took glances longer than $2.5 \mathrm{~s}$ for $45 \%$ of the tasks compared to $10 \%$ for experienced (average age 23.9 years) drivers. Both Chan et al. and Wikman et al. found that there was no significant difference between the groups in terms of total time spent on the task. In other words, the experienced drivers took shorter but more frequent glances away from the forward roadway than did inexperienced drivers.

Although it might be argued that it is never safe to look away from the forward roadway, drivers must frequently do so to perform normal, important driving tasks. For example, drivers must look away from the forward roadway to check the rearview or side mirrors, to search for and activate hazard lights, or for a number of other safety-critical tasks. It is unknown, however, how long a glance away from the forward roadway must be to compromise safety. In a recent simulator experiment by Horrey and Wickens (2007), glances away from the roadway for 1.6 seconds or longer constituted only a relatively small fraction of the total glances $(22 \%)$, but were responsible for the great majority of crashes $(86 \%)$. These findings were consistent with the naturalistic study reported by Klauer et al. (2006) in which glances longer than $2 \mathrm{~s}$ increased crash risk significantly.

Getting drivers to reduce the duration of glances away from the roadway, however, is a difficult charge given all of the distractions in today's vehicles. Also, it is not clear if the willingness of young inexperienced drivers to look away from the forward roadway for especially long periods of time is due to their failure to understand the consequences of such long glances, lack of situation awareness, or increased risk taking behavior (Lee et al., 2006).

One approach to reducing crashes resulting from distractions is to remove the distraction itself. For example, some States have outlawed the use of hand-held cell phones. These efforts rely on people obeying the law. An alternate approach to the problem is to provide training that teaches drivers to better manage their glances and attention to the roadway. In essence, the training seeks to ingrain a safer glance pattern with a markedly lower risk of leading to a crash.

The current research effort included three studies related to the development and evaluation of the FOCAL training program. Study 1 comprised the development of the FOCAL program and a PC-based evaluation of its effectiveness. Study 2 included a field evaluation of the effectiveness of the FOCAL program, and Study 3 consisted of an evaluation of the program's effectiveness in a driving simulator. Each study is described in detail below. A summary discussion section reviews the implications of the findings for future research. 


\section{STUDY 1: FOCAL DEVELOPMENT AND COMPUTER-BASED EVALUATION}

Simply training drivers never to glance away from the forward roadway could be unsafe because glances at gauges, warning lights, and mirrors might actually serve to decrease crash risk. Also, given the large number of distractions in modern vehicles (e.g., radio/entertainment systems, cellular phones), it would be naive to think that drivers could voluntarily ignore the temptation to look away from the forward roadway while they are driving. Experienced drivers likely learn from experience how long they can glance away from the roadway and still maintain safety. It is reasonable to assume that safety for novice drivers can be improved if they can be trained early in their driving careers to avoid long glances when performing in-vehicle tasks. The same strategy should be effective both for important driving-related tasks (e.g., turning on the emergency flashers) and for in-vehicle tasks that are not specific to the driving task (e.g., finding a $\mathrm{CD}$ in a case). The sections below describe the study methods and results for a PCbased evaluation of the FOCAL program. Appendix A includes a full description of the FOCAL program with selected screenshots from the actual program.

\subsection{Method}

Participants were administered the Attention Maintenance Assessment Program (AMAP) described below, both before and after training in an attempt to measure the effects of the training. Participants completed either the newly developed FOCAL training or a Placebo training course. The placebo training took about the same time as training with FOCAL, but was not related to attention maintenance. It involved asking participants to remember the implication of various traffic signs, signals, and pavement markings for safe movement of their vehicle.

\subsubsection{Participants}

A total of 30 participants completed the study, 28 males and 2 females. All participants were students at the University of Massachusetts Amherst. Participants were paid \$25 for participation.

\subsubsection{Materials}

Attention Maintenance Assessment Program (AMAP). AMAP used an innovative approach to determine if drivers were glancing away from the simulated roadway on the computer screen. In AMAP, novice and experienced drivers were asked to perform two concurrent tasks displayed on a laptop computer screen. The computer screen was split in half horizontally with one task on the top and the other on the bottom of the screen. Only one task, however, could be viewed at a time. The participants had to toggle between the tasks to successfully complete each.

The task displayed at the top of the screen involved identifying potentially threatening vehicles, pedestrians, and bicyclists in a video recording of a drive down a local roadway (Figure 1). As the video progressed, participants had to indicate, via a key press, when a threat passed through either of two vertical, bands on the screen as shown in Figure 1. The other task, 
displayed on the bottom half of the computer screen, required drivers to determine if a particular street was contained on the displayed map (Figure 2).

Participants were told that they needed to correctly identify as many potential threats in the video as possible (top task) while also correctly determining if the streets of interest were actually on the map (bottom task). When the map task was initiated by the participant using a key press, the top half of the screen showing the video went black and the map view appeared in the bottom half of the screen. Although blacked out, the video continued to play in real time in the background. Thus, when the participant toggled to the map view and the video was out of sight, potential hazards might still have been materializing in the hidden top task.

The frequency and duration of the viewing of each task was recorded for all participants. At the end of each video segment, participants indicated by checkboxes whether or not they saw the streets on the map.

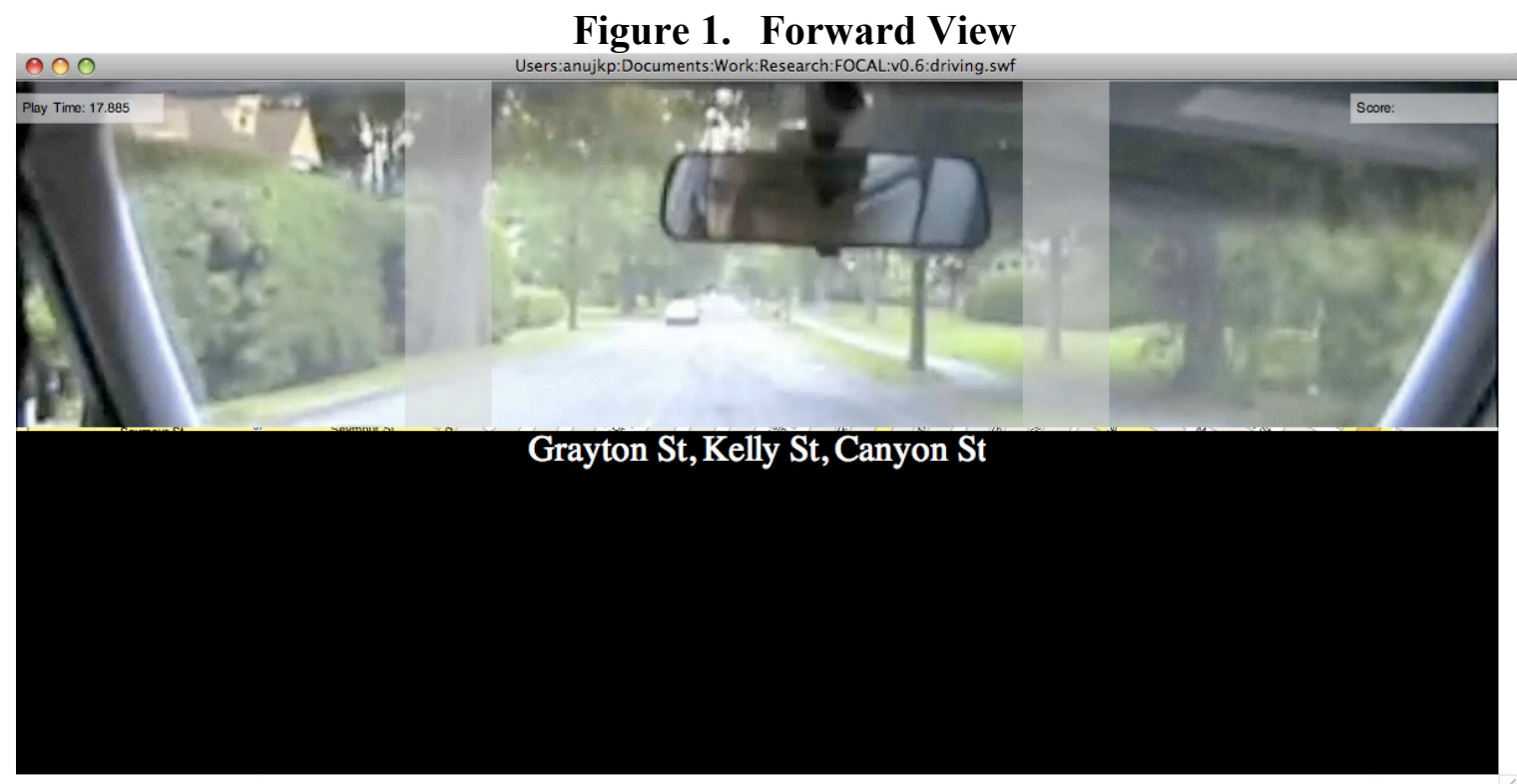

AMAP included four video segments, each approximately one minute in length, depicting downtown Amherst. Street signs, traffic signs, pedestrians and traffic appeared throughout the videos. Each trial (video) began with the forward roadway view. Participants pressed the spacebar on the computer keyboard to toggle to the map view. The enter key was used both to toggle back to the forward view and to indicate that a traffic sign, pedestrian or opposing vehicle was passing through one of the vertical target bars that were superimposed on the forward view (Figure 1).

At the beginning of each trial, the participant was presented with three street names, and they were always listed at the bottom of the forward view. At the end of the trial, the participant was asked if he or she had seen each of the three street names on the map. All three street names were actually on the maps used in the first three trials. Only two of the three street names were present in the fourth trial. Data from the pre-test were actually used as part of the FOCAL 
training, so participants could see how they behaved and the potential consequences of those behaviors.

Figure 2. Map View

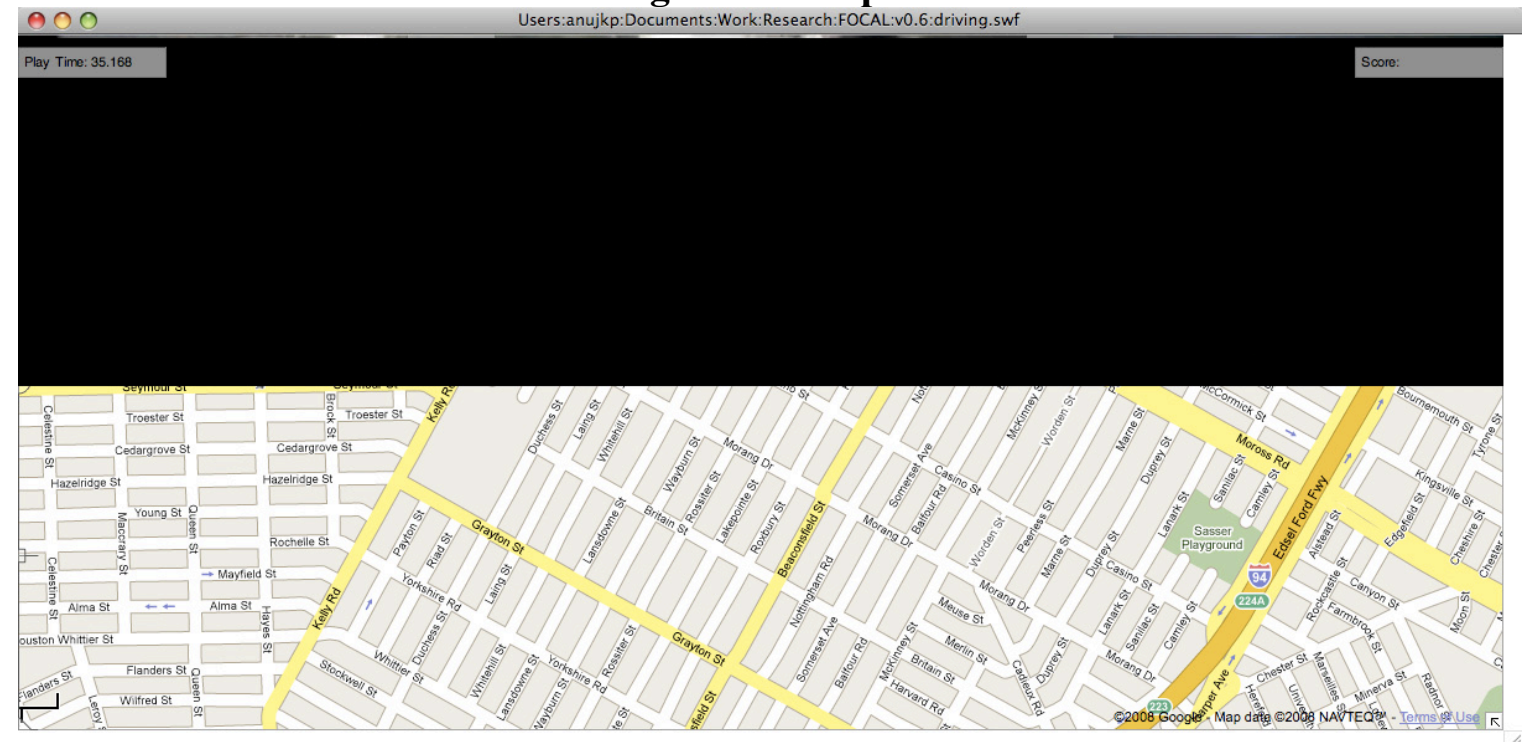

Prior to its use in this study, AMAP was used in another task related to the Risk Awareness and Perception Training (RAPT). As part of that investigation by Fisher et al. (2010), both young novice drivers and older more experienced drivers (35-55 years old) completed AMAP. The results indicated that younger and older drivers performed differently on AMAP with the older drivers spending less time on each toggle to the map task than did the younger drivers. This suggested that the PC-based AMAP was capable of detecting differences in glance durations among young novice drivers and older experienced drivers.

FOCAL Training. A detailed description of FOCAL is provided in Appendix A along with estimates of the time it takes to complete each section and subsection. FOCAL training started with practice on the PC-based driving and map task. This practice was followed by the AMAP pre-test described above. The program then provided the user with feedback about performance on the pre-test by actually showing him or her what it looked like when long glance durations were taken during the pre-test. FOCAL then demonstrated what a 3-second glance looks and feels like. For this demonstration, the user completed a drive and map search task similar to that in the pre-test that required toggling back and forth to successfully complete both tasks. The training version, however, did not allow the user to glance at the map for more than 3 seconds. At 3 seconds, the screen automatically returned to the road view. The next training section allowed the user to toggle between the two views, and did not automatically change screens. Although the program did not switch views automatically, the system generated an audible tone when a glance exceeded 3 seconds. The same type of training was then performed for 2-second glances. Again, the system demonstrated what a 2-second glance looks like by automatically changing back to the road task when a glance exceeded 2 seconds. The final training section allowed the user control of the toggling but the system beeped when glances were too long. The participant then completed the AMAP post-test. 
Placebo Training. This training material was retrieved from the Massachusetts Registry of Motor Vehicle's Driver's Manual (2009). Participants read about the implications of various signs, signals and pavement markings for the behavior of a driver. They were then given 10 questions. For example, the participants might be asked: "What should you do if a signal light is blacked out and not functioning?" They then had space to write an answer. The answer in this case is: "If signals are blacked out and not functioning, you should be cautious and treat the intersection as having stop signs in all directions. Proceed when it is safe to do so." If they answered one or more questions incorrectly, they were asked to re-read the material and answer a new set of questions (see Appendix B).

\subsubsection{Design}

The design involved two main variables, period (pre-training versus post-training) and training group assignment (placebo or FOCAL) . With respect to training group, participants were randomly assigned to either the placebo or FOCAL training programs. All participants completed both the AMAP pre-test and post-test. Glance durations before and after exposure to training were the primary dependent variables. Other measures of interest included total time with eyes off the roadway and accuracy on the map task.

\subsubsection{Procedure}

All participants began with the AMAP pre-test. They then participated in either the placebo or FOCAL training. Finally, they were given the AMAP post-test.

\subsection{Analysis and Results}

For simplicity and ease of interpretation, t-tests were used for all comparisons of interest. Three sets of results are presented below: (1) the percentage of glances away from the forward roadway on the pre-test and post-test that were longer than specific thresholds; (2) the total time spent on the map task in both the pre-test and post-test; (3) the accuracy of each group in the map task on both the pre-test and post-test.

\subsubsection{Effect of Training on Glance Behavior}

Figure 3 shows the distribution of glance durations for the placebo-trained group. If anything, after training the participants in the placebo group appeared to become slightly more willing to engage in long glances at the bottom map task and away from the top, driving task. For example, the percentage of glances longer than 4.0 seconds on the pre-test was approximately $20 \%$. The precentage increased to almost $30 \%$ on the post-test. T-tests were used to test the statistical significance of the changes from pre to post for each of the glance threshold values for the placebo group. None of the changes were statistically significant ( $p s>0.05)$ which suggests the placebo group behaved virtually the same on the pre- and post-tests. 
Figure 3. Distribution of Glance Durations on AMAP Before and After Placebo Training

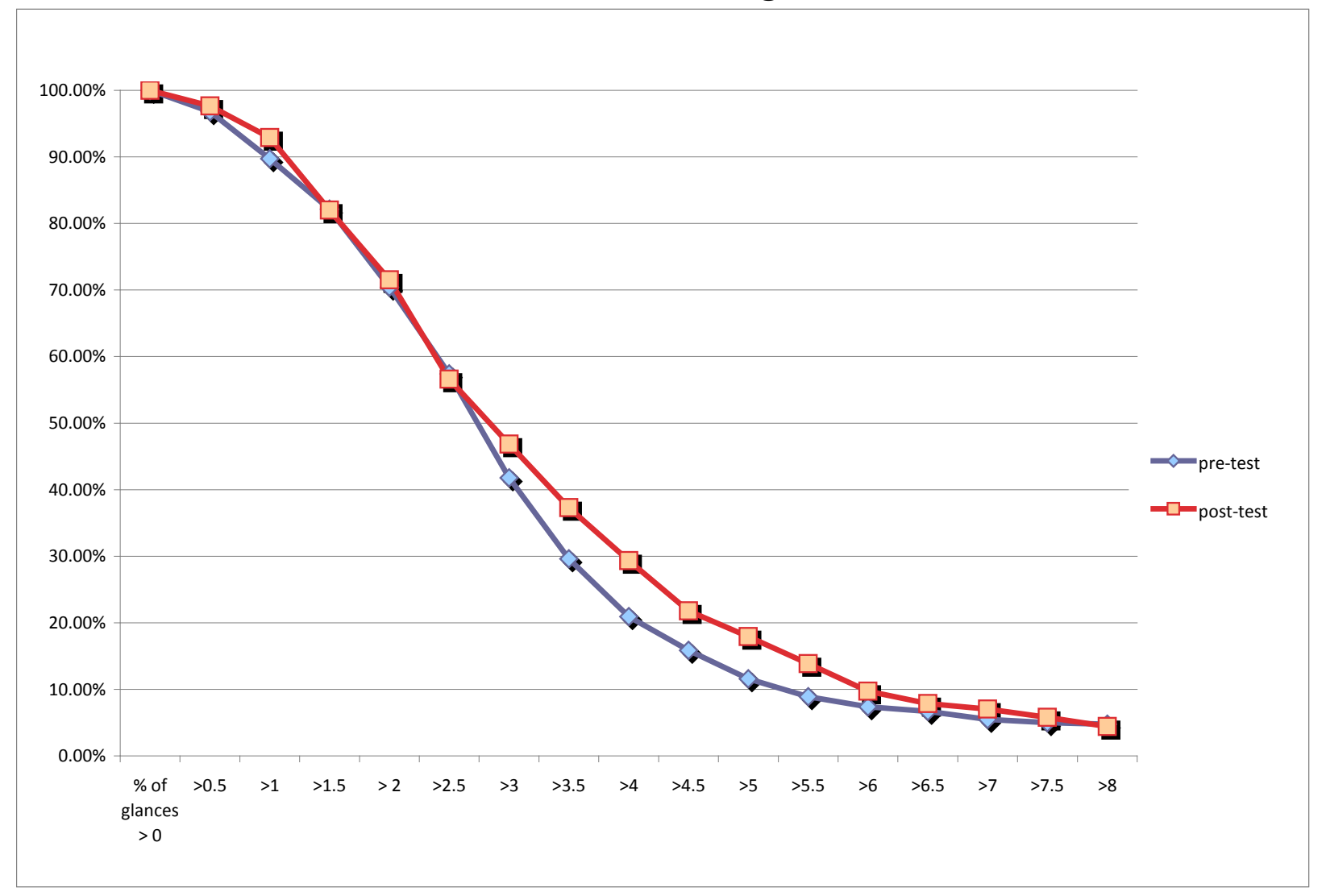

The pre-test and post-test scores for the FOCAL trained group are displayed in Figure 4. The training led to dramatic decreases in glance durations from pre-test to post-test. T-tests were used to test the statistical significance of the changes from pre to post for each of the threshold values for the FOCAL group. Table 1 shows that the changes were statistically significant $(p s<0.05)$ for all glance thresholds below $7.5 \mathrm{~s}$, which suggests a substantial training effect. 
Figure 4. Distribution of Glance Durations on AMAP Before and After Focal Training

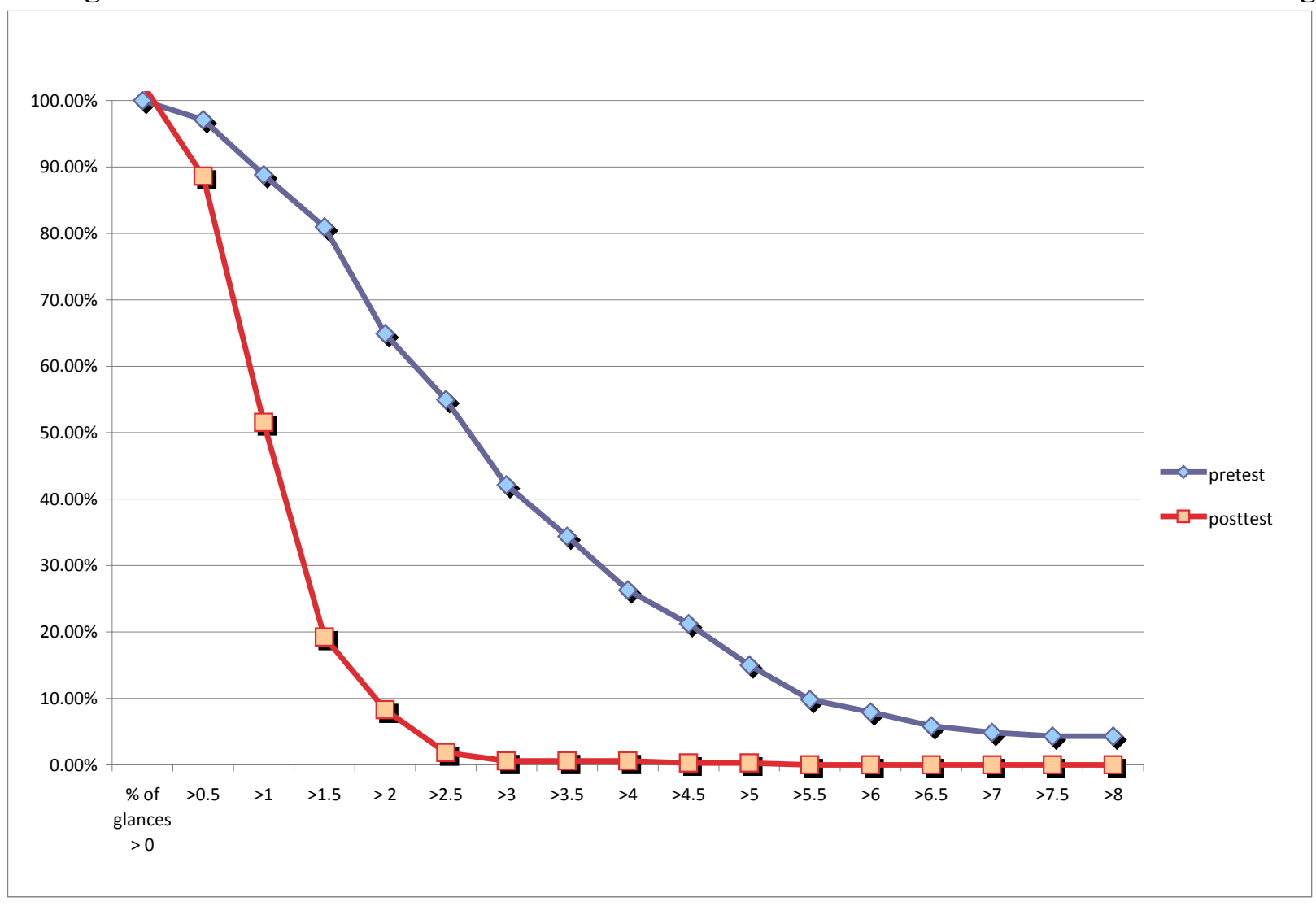

Table 1. Comparison of FOCAL Training Group's Pre/Post Differences on AMAP

\begin{tabular}{|l|r|r|r|r|}
\hline $\begin{array}{l}\text { Glance } \\
\text { Duration } \\
\text { (in seconds) }\end{array}$ & \multicolumn{1}{|l|}{ Difference } & \multicolumn{1}{l|}{$\begin{array}{l}\text { Standard } \\
\text { Error }\end{array}$} & t statistic & \multicolumn{1}{l|}{ p value } \\
\hline$>0.5$ & 0.104 & 0.047 & 2.229 & 0.043 \\
\hline$>1$ & 0.378 & 0.079 & 4.764 & 0.000 \\
\hline$>1.5$ & 0.618 & 0.058 & 10.591 & 0.000 \\
\hline$>2$ & 0.566 & 0.041 & 13.936 & 0.000 \\
\hline$>2.5$ & 0.531 & 0.050 & 10.611 & 0.000 \\
\hline$>3$ & 0.416 & 0.067 & 6.222 & 0.000 \\
\hline$>3.5$ & 0.338 & 0.063 & 5.330 & 0.000 \\
\hline$>4$ & 0.257 & 0.061 & 4.251 & 0.001 \\
\hline$>4.5$ & 0.209 & 0.052 & 4.039 & 0.001 \\
\hline$>5$ & 0.148 & 0.043 & 3.452 & 0.004 \\
\hline$>5.5$ & 0.098 & 0.032 & 3.059 & 0.008 \\
\hline$>6$ & 0.080 & 0.029 & 2.742 & 0.016 \\
\hline$>6.5$ & 0.059 & 0.027 & 2.146 & 0.050 \\
\hline$>7$ & 0.049 & 0.025 & 1.912 & 0.077 \\
\hline$>7.5$ & 0.043 & 0.025 & 1.729 & 0.106 \\
\hline$>8$ & 0.043 & 0.025 & 1.729 & 0.106 \\
\hline
\end{tabular}

${ }^{a}$ Difference is equal to the proportion of the FOCAL-trained group's pre-test glances minus the same group's proportion of glances after training. 
An analysis of the FOCAL and placebo group AMAP pre-test glance durations showed no significant differences $(p s>0.05)$. Therefore, the primary comparisons of interest were between the post-test mean percentage of glances above specific durations for the FOCAL trained and placebo trained participants. As an example of the magnitude of the differences between the training groups on the post-test, the mean percentage of glances greater than 0.5, 2.0 and 4.0 seconds for the placebo group were $97.7 \%, 71.5 \%$ and $29.3 \%$, respectively, compared to the FOCAL group times of $86.7 \%, 8.3 \%$ and $0.6 \%$. T-tests were used to separately test the statistical significance of the differences in the average proportion of glances greater than $\mathrm{x}$ seconds $(\mathrm{x}=0.5,1.0,1.5, \ldots 8.0)$ on the post-test for the placebo and FOCAL groups. These differences were statistically significant for all glance durations less than $8.0 \mathrm{~s}$ (Table 2) which again shows a substantial training effect for FOCAL training when compared to the placebo trained group.

Table 2. Comparison of Post-Test Placebo and Post-Test FOCAL AMAP Scores

\begin{tabular}{|l|l|l|l|l|}
\hline $\begin{array}{l}\text { Glance } \\
\text { Duration } \\
\text { (in seconds) }\end{array}$ & Difference $^{\mathrm{a}}$ & $\begin{array}{l}\text { Standard } \\
\text { Error }\end{array}$ & t statistic & p value \\
\hline$>0.5$ & 0.1099 & 0.0508 & 2.1641 & 0.0391 \\
\hline$>1.0$ & 0.4185 & 0.0890 & 4.7009 & 0.0001 \\
\hline$>1.5$ & 0.6285 & 0.0717 & 8.7609 & 0.0000 \\
\hline$>2.0$ & 0.6323 & 0.0681 & 9.2864 & 0.0000 \\
\hline$>2.5$ & 0.5477 & 0.0743 & 7.3706 & 0.0000 \\
\hline$>3.0$ & 0.4627 & 0.0774 & 5.9758 & 0.0000 \\
\hline$>3.5$ & 0.3672 & 0.0795 & 4.6168 & 0.0001 \\
\hline$>4.0$ & 0.2875 & 0.0786 & 3.6587 & 0.0010 \\
\hline$>4.5$ & 0.2151 & 0.0672 & 3.1997 & 0.0034 \\
\hline$>5.0$ & 0.1763 & 0.0619 & 2.8484 & 0.0081 \\
\hline$>5.5$ & 0.1386 & 0.0532 & 2.6078 & 0.0145 \\
\hline$>6.0$ & 0.0971 & 0.0406 & 2.3893 & 0.0239 \\
\hline$>6.5$ & 0.0786 & 0.0339 & 2.3209 & 0.0278 \\
\hline$>7.0$ & 0.0704 & 0.0318 & 2.2166 & 0.0349 \\
\hline$>7.5$ & 0.0580 & 0.0268 & 2.1650 & 0.0391 \\
\hline$>8.0$ & 0.0440 & 0.0224 & 1.9645 & 0.0595 \\
\hline
\end{tabular}

${ }^{a}$ Difference is equal to FOCAL post-test glance proportion minus placebo post-test glance proportion.

\subsubsection{Total Time and Accuracy}

The results above demonstrate that the participants trained with FOCAL were indeed taking shorter glances away from the forward roadway (top task) after training. It was also important, however, to determine if the FOCAL training group showed any changes in the total time they were spending with eyes off the roadway (away from the top task) compared to the placebo training group. As seen in Table 3, the FOCAL group spent less total time on the map task than did the placebo group during both the pre-test and post-test. Only the difference during the pre-test was statistically significant, $\mathrm{t}(28)=2.859, \mathrm{p}<0.01$. As Table 3 reveals, both groups showed decreases in the total time spent on task after training, but neither change was statistically significant ( $p s>0.05)$. The difference between the groups also decreased after training, but the decrease was not significant $(p>0.05)$. 
Table 3. Total Time Spent on the Map Task

\begin{tabular}{|l|r|r|r|}
\hline & \multicolumn{1}{|l|}{ Pretest } & Posttest & Difference \\
\hline FOCAL & 15.631 & 14.701 & 0.930 \\
\hline Placebo & 22.162 & 18.655 & 3.507 \\
\hline Placebo - Focal & 6.531 & 3.955 & 2.577 \\
\hline
\end{tabular}

Also of concern was how accurately participants performed the map task and how FOCAL training affected the accuracy of trainees. The intent of FOCAL was not necessarily to change performance on the map task, nor was it the goal to change behavior such that the participants could not perform the map task as well as they did before training because they thought it best to never look down. Therefore, a measure of accuracy on the map task was calculated. This measure was simply the percentage of streets correctly identified as present or absent on the map task. Averaging over all participants in a group, the map accuracy for the FOCAL trained group increased from $61.1 \%$ to $71.7 \%$ from pre-test to post-test. For the placebo group, accuracy increased from $64.6 \%$ to $71.9 \%$ from pre-test to post-test. Averaged over the two groups, the $8.9 \%$ improvement from pre-test to post-test was significant, $\mathrm{t}(28)=2.812$, $p<0.01$, which indicates an overall practice effect for all participants. However, the $3.3 \%$ difference between these two improvement scores was not significant, $\mathrm{t}(28)=0.52, p>0.05$. This pattern of results suggests that FOCAL neither improved nor harmed overall accuracy on the map task compared to the placebo training. The improved post-test performance on the map task for both groups also suggests that participants were not shedding the map task to focus on the upper, driving-related task.

\subsection{Discussion}

The FOCAL training changed participant glance behaviors as measured by AMAP in the desired direction. This suggests that FOCAL would achieve its goal of reducing the duration of glances away from the forward roadway. This was most evident with the precipitous drop in the percentage of glances to the map task over 2 seconds after FOCAL training (from $64.9 \%$ on the pre-test to $8.3 \%$ on the post-test). In addition, this change in the distribution of glance durations did not come at the expense of accuracy on the map task as FOCAL participants actually improved their accuracy after training.

Despite these positive results, there are clear limitations as to the generalizations that can be made from this initial evaluation. First, the evaluation of FOCAL was conducted on a computer using AMAP for which the transfer function to actual driving has not been quantified. Thus, the training effects cannot be generalized to a simulator or, more importantly, to the field. Second, the assessment and training were conducted with a map task as the primary distractor task. It is not clear if the effects observed when using the map task would generalize to other invehicle tasks that may be more or less distracting. Also, participants were "forced" to perform the map task and were told they needed to complete the task accurately, something that may not be completely realistic on the road. Finally, the post-test was completed immediately after training, and the training effects could diminish with time. 


\section{STUDY 2: FIELD EVALUATION OF FOCAL}

Given the positive findings from the PC-based evaluation of the FOCAL training, it was reasonable to continue to evaluations of FOCAL in a driving simulator and on the road in real traffic. Due to logistical constraints involving availability of the simulator, the next step was an evaluation of the training's effectiveness via a field test involving young drivers in real driving conditions. The following sections describe the study methods and results.

\subsection{Method}

The following sub-sections provide details on the study participants, materials, procedures, analyses, and results.

\subsubsection{Approach}

The basic study approach involved recruiting participants to drive a predetermined route in actual traffic. The participants were high school students with limited driving experience. A certified driving instructor was in the right seat of the dual-brake car and had the responsibility for the safety of the drive and for navigation to stay on the route. A researcher sat in the back seat. At predetermined points during the drive, the researcher requested that the driver perform a secondary task that had the potential to cause the driver to glance away from the roadway for an extended period of time. Driver glance duration was the primary evaluation measure.

\subsubsection{Participants}

Participants were recruited from Millburn High School in Millburn, New Jersey, to participate in the study. With permission from the school administration, physical education teachers asked students in their classes to volunteer. The students were provided a flyer that briefly described the study's requirements. The flyer indicated that students could only participate if they had a learner's permit and at least 5 hours of driving experience, or had held a restricted driver's license for less than 6 months. Eligible students called the experimenters and scheduled a time slot on one of three study weekends. The physical education teachers provided the students with the necessary parental consent and student assent forms that would be needed for participation. Students were instructed to bring the signed parental consent forms with them to the study.

A total of 40 students signed up for the study. Of these, 39 actually appeared at their scheduled time for the study and were randomly assigned to FOCAL or placebo training. One participant did not complete a drive because the eye tracker used to measure where the participant was looking could not be calibrated due to excessive glare from the individual's eye glasses. Of the remaining 38 participants, viable eye tracker data were obtained for 37 . A total of 19 of these ( 10 males, 9 females) completed the FOCAL training. The remaining 18 (11 males, 7 females) completed placebo training. Participant age ranged from 16 years 0 months to 17 years 0 months. Mean ages of the FOCAL and placebo training groups were 16 years 8 months and 16 years 9 months, respectively. All participants were paid $\$ 50$ for participation. In addition, $\$ 50$ was paid to the school for recruiting each participant. 


\subsubsection{Study Dates}

The study was conducted over a span of 4 weeks with data collection taking place on three weekends at the Millburn High School. Data collection began at 9 a.m. each day and usually concluded around 3 p.m. The data collection dates were:

- November 21, 2009;

- December 5-6, 2009; and

- December 12-13, 2009.

Weather and driving conditions varied greatly on these days. The first weekend was sunny and mild with good driving conditions. The second weekend included snow and icy road conditions. The third weekend was sunny and cool with good driving conditions. The experimental design compensated for these weather differences so they would not confound the main comparison of the FOCAL-trained and placebo groups.

\subsubsection{Materials}

Folders. Folders were created for the FOCAL and placebo training groups. Each folder included instructions to the participant. Also included in each folder were a demographics questionnaire, a task list for the in-car experimenter, a video tape for the eye tracker, and a receipt form to be completed once the participant was paid. The placebo group folders also included a packet of papers used for the placebo training since it was not PC-based.

Computers. Four identical personal laptop computers were used for the study, two for FOCAL training and two for placebo training. Laptops were placed on individual desks in four corners of a large classroom.

AMAP. The AMAP used in Study 1 was used before and after administration of the FOCAL and placebo training.

FOCAL Training. The FOCAL training developed in Study 1 was used here for the experimental training group.

Placebo Training. Placebo training consisted of the same Rules of the Road paper packet used in Study 1.

Eye Tracker. A portable lightweight eye tracker (Mobile Eye developed by Applied Science Laboratories) was used to collect the eye-movement data for each driver. It had a lightweight optical system consisting of an eye camera and a color scene camera mounted on a pair of safety goggles. The images from these two cameras were interleaved and recorded on a remote recording system, thus ensuring no loss of resolution. The interleaved video was then transferred to a PC where the images were separated and processed. The eye movement data were converted to a crosshair, representing the driver's point of gaze, which was superimposed upon the scene video recorded during the drive. This provided a record of the driver's point of gaze on the driving scene while driving on the active roadway. The remote recording system 
was battery powered and was capable of recording up to 90 minutes of eye and scene information at $60 \mathrm{~Hz}$ in a single trial.

Vehicles. Two identically equipped Honda Civics belonging to a licensed driving school were used for this study. Each was an automatic transmission with standard Honda Civic systems and displays. The vehicles were each outfitted with dual foot pedal brakes that were placed in front of the right front seat that was occupied by a licensed driving instructor from the school that owned the cars. The vehicles carried a "Student Driver" sign on top.

Secondary Tasks and Task Materials. The secondary tasks included a mixture of vehicle/driving tasks and nondriving tasks. The vehicle/driving tasks included turning the headlights on high beam, activating the front windshield defroster, and activating the emergency flashers. The non-vehicle tasks included tuning the radio, looking for a specific CD in a case holding $10 \mathrm{CDs}$, trying to find a street on a map, and taking 40 cents out of a cup holder. In one instance the specific CD requested was present in the case, and in the other it was not present. Similarly, in one map task the street was on the map while in the other it was not. For the change task, 10 coins where placed in the cup holder, but only one combination of coins added up to 40 cents (one quarter, one dime, one nickel).

Driving Course and Task Instructions. The driving course began in the Millburn High School parking lot and continued on local streets around the high school (see Figure 5). The research team worked with the driving school staff to select roadways that had a variety of traffic situations, but were sufficiently safe (e.g., had enough room for drivers to wander from their lane) for participants to complete the tasks while driving. Two of the streets (Millburn Avenue and Main Street) were two-lane arterial roadways that had a fair amount of traffic that was separated by a double yellow line. These streets had numerous commercial driveways entering the roadway, cars parked alongside the road, and traffic lights. The remaining streets were twolane (unmarked) neighborhood streets with very light traffic. These neighborhood streets, however, did have numerous cars parked alongside them, numerous residential driveways, and some stop signs. All turns were right-hand turns, and some roadways were traversed multiple times with different tasks being completed each time. 


\section{Figure 5. Area in Which Drive Took Place}

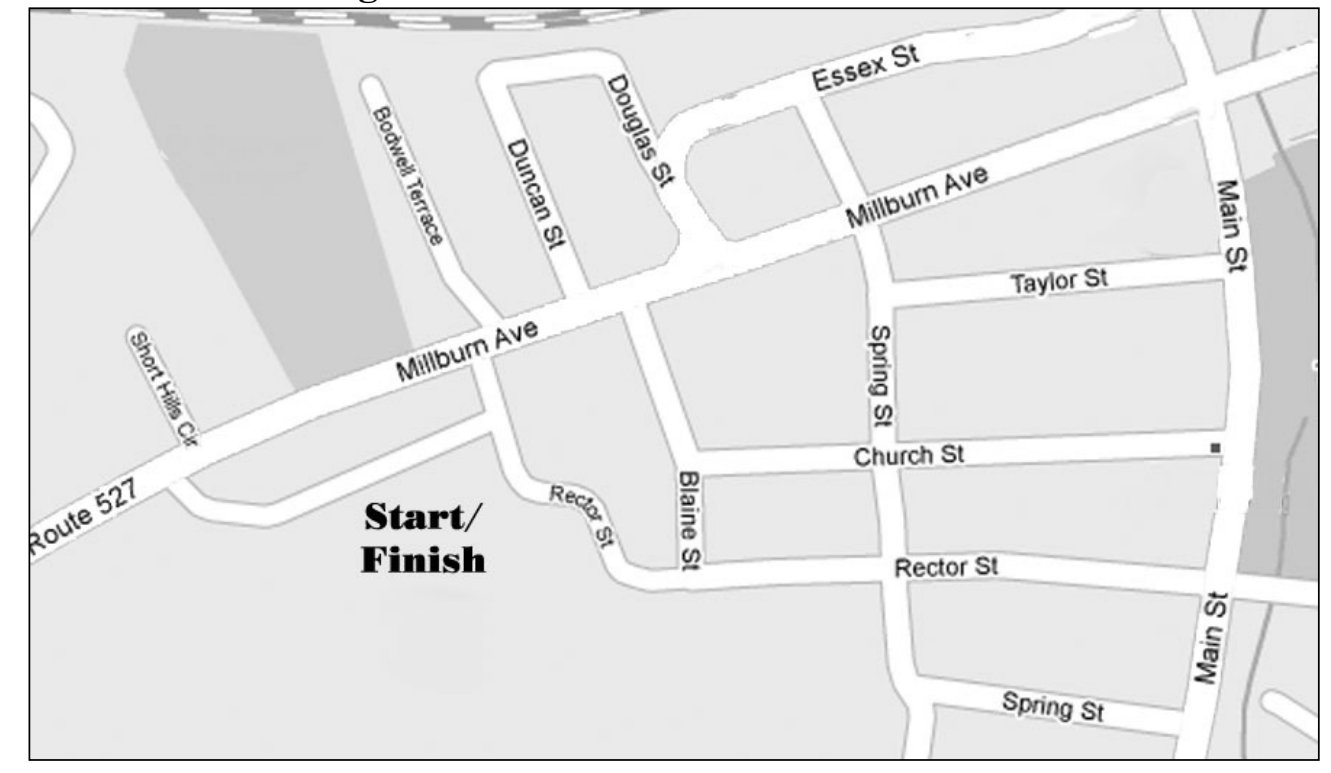

The instructions for the experimenter to control the secondary tasks are listed below for each roadway on the course (see Figure 6). The instructions also permit the reader to follow the course on Figure 5. The course begins at the start/finish point in the parking lot. The first turn into real traffic is a right turn onto Millburn Avenue just to the right of the words "Route 527" on Figure 5.

The tasks in steps 3, 5, and 11 were considered vehicle/driving tasks because they involved finding and using vehicle controls used to make driving easier and/or safer (headlights, defroster, and emergency flashers). The other six tasks were considered non-vehicle tasks because they did not directly relate to the operation of the vehicle.

\subsubsection{Design}

The experimental design was a between subjects design with training type (FOCAL or placebo) as the between subjects variable. Glance durations away from the roadway during the field drive were the primary dependent variable.

\subsubsection{Procedures}

Check-in. When a participant arrived, a staff member checked the person in before sending the individual to training. The staff member first collected the participant's consent form and confirmed it was signed by a parent. The participant was then asked to sign the assent portion of the form to confirm they wished to participate in the study. The staff member also checked the participant's license/permit to make sure it was valid and matched the name on the consent form.

Assignment to Training Group. A staff member took a folder with the study materials in it and assigned it to the participant at check-in. The folders either contained FOCAL or placebo 
training material. Assignment to FOCAL or placebo group was alternated with each arriving participant. Therefore, no participant was assigned to the same group as the previous participant. Once the participant was assigned to a group, a staff member walked the participant to the training room and handed the folder to another staff member who was directing the training. Based on the group assignment, the trainer seated the participant at the appropriate computer.

\section{Figure 6. Secondary Task Sequence Controlled by Experimenter}

1. (Practice Task) After the driver backs out of the parking space and starts driving forward, instruct the driver to "roll-down the driver side window half-way." After the task has been completed, ask the driver to roll the window back up.

2. (Practice Task) When the driver goes down the practice straight-away, instruct the driver to "call out your current speed."

3. As soon as the driver turns on to Millburn Avenue, instruct the driver to "turn on the headlights and activate the high beams." If the task was completed, ask the driver to turn the headlights off.

4. As soon as the driver turns on Spring Street, instruct the driver to "find the Andrea Bocelli $\mathrm{CD}$ in the CD case on the console and take it out." If the task was completed, ask the driver to give the $\mathrm{CD}$ to the driving instructor.

5. As soon as the driver turns on Rector Street, instruct the driver to "turn on the front window defroster with the blower on high." If the task was completed, ask the driver to turn off the defroster.

6. Blaine Street has no task

7. As soon as the driver turns on Church Street, ask the driver "On the map on the console, what road intersects with Towson Lane?" The street is not on the map. Stop the driver from looking after 20 seconds.

8. After the stop sign on Church Street, instruct the driver to "turn on the radio and tune it to AM 1210." If the task was completed, ask the driver to turn off the radio.

9. Main Street has no task.

10. As soon as the driver turns on Rector Street, ask the driver "On the map on the console, what road intersects with Bertmore Drive?" If the task was completed, ask the driver to put down the map.

11. After the stop sign on Rector Street, instruct the driver to "turn on the emergency four-way flashers." If the task was completed, ask the driver to turn off the flashers.

12. Blaine Street has no task.

13. As soon as the driver turns on Church Street, instruct the driver to "find the Michael Buble CD in the CD case on the console and take it out." The CD is not in the case. Stop the driver from looking after 20 seconds.

14. Spring Street has no task.

15. After a short delay on Rector Street, instruct the driver to "find exactly forty cents in the cup holder to your right and give it to the driving instructor." If the task was completed, ask the driver to continue driving back to the parking spot where the drive started.

Training. The participant was first given the training instructions contained in the folder. Any questions were answered. The participant then filled out the demographics form. All participants then completed AMAP. After the first AMAP test, the participant took either the FOCAL or placebo training. Those in the FOCAL training group simply continued working on the computer and followed the on-screen instructions. Any questions about the FOCAL program were answered before FOCAL training began. After the FOCAL training, the participant then completed another AMAP test. Participants in the placebo group were instructed by the 
computer program to stop working on the computer and complete the Rules of the Road training. Participants were given the paper training packet and told they would be tested after they finished reading the packet. When a participant was done reviewing the packet, he or she was given the test and told the test was open book. After the open-book paper and pencil test, the participant completed the second AMAP test. ${ }^{1}$ FOCAL and placebo training each took anywhere from 30 minutes to one hour to complete depending on the participant. After training, the participant was escorted to the vehicle where the on-road drive was to take place. The participant was given an instruction sheet that described the next portion of the study and the eye tracker calibration process.

Eye Tracker Calibration. The experimenter performing the eye calibration and test drive was not told if the participant was in the FOCAL or placebo training group. Once the participant arrived at the vehicle, he or she was seated in the vehicle and allowed to adjust the seat and mirrors to a comfortable driving position. The driver was then instructed to put on the seat belt. Once the participant was settled in his or her driving position, the eye tracker glasses were put on and adjusted to be comfortable. The eye tracker was then calibrated per the manufacturer's instructions. If a participant moved during calibration, or if the glasses slipped, the calibration process had to be repeated. The calibration process took anywhere from 5 to 15 minutes.

The Drive. After the eye tracker was calibrated the experimenter sat in the back seat of the vehicle. The driving instructor was seated in the front passenger seat and could activate the dual brake system or take the wheel if necessary. The participant was reminded that all driving instructions would be given by the driving instructor and all secondary task instructions would come from the experimenter in the back seat. The experimenter then explained that the tasks may involve any of the vehicle system controls or the materials (CD case, map, or coins) on the center console between the driver and instructor. The participant was instructed to attempt to complete the tasks while driving safely. Once the participant indicated that he or she understood the instructions, the drive began.

The two practice tasks were conducted as the participant drove out of the high school's parking lot. The remaining nine tasks were completed on active roadways. Each task was started immediately after the participant made a turn or after a stop sign unless there was a reason to delay the task (e.g., oncoming vehicles in the path of the study vehicle). Each task was completed on the designated street, and all participants completed tasks in the same order and on the same streets. When on the residential roads, the driving instructor asked the participant to drive no more than 17 miles per hour. The actual time allotted to each task varied by participant since some participants would complete a task very quickly while others never completed the task at all. Generally, the experimenter allowed a participant about 20 seconds to try to complete a task. If the participant did not successfully complete the task in the allotted time, the experimenter instructed him or her to stop trying. In a few instances, a person may have been given more time to complete a task if something out of the ordinary occurred in the middle of attempting a task (e.g., a bus full of people going to a parade went by very slowly). In other

\footnotetext{
${ }^{1}$ The pre- and post-training AMAP tests involved searching for different street names on the map. To avoid possible confounding of the results if one set of streets were easier to find than the other, the order of presentation was counterbalanced across the participant population. This was accomplished by using four computers - two each for the FOCAL and placebo training.
} 
instances, the time to complete a task may have been shorter if a participant drove faster than instructed and arrived at a stop sign or other change of direction point on the roadway much more quickly than other participants. The experimenter recorded task success or failure. A task was recorded as a failure if the participant ran out of time or attempted the task but performed it incorrectly. As described earlier, two of the tasks could not be successfully completed since the items being searched for (CD and street on a map) were not present. After completing the final task, the participant drove back to the high school and parked the vehicle in front of the calibration grid. The videotape with the eye tracker data was ejected and placed in the participant's folder. After the eye tracker was removed, the participant was taken to the checkout table and paid $\$ 50$ for participation. The experimenter answered participants' questions at that point.

\subsection{Data Reduction and Analysis}

The tapes were sent to UMass for data reduction and analysis. Each tape was marked with a randomized identification number. The UMass researchers doing the data reduction and analysis were not given the key to determining which numbers were experimental (FOCAL training) tapes and which were generated from participants who received placebo training.

Various measures were computed from the driver's pattern of eye movements that were scored on a frame-by-frame basis from the eye tracker video data $(30 \mathrm{~Hz})$. The video output of the eye tracker contains crosshairs superimposed on a view of the driver's forward view, with the crosshairs representing the driver's point of gaze on the forward view. However, the primary coding was of the locations of fixations. More specifically, the fixations were coded as either being on road or off road. Audio was recorded on the eye tracking videos, allowing the scorer to hear when the participant was instructed to begin and end a secondary task. While the participant was performing the task, the scorer recorded the time stamp for the video frames each time the participant's point of gaze transitioned from either on to off road or vice versa. A transition was recorded anytime the participant's point of gaze crossed the boundary between the test vehicle's windshield and dashboard.

The primary unit of analysis was the duration of a glance rather than the duration of individual fixations. A glance is defined as a series of successive fixations that are either on road or off road. The results below focus on the duration of off-road glances as the measure of inattention to the forward roadway. In addition, the only parts of the drive that were analyzed for eye movement behavior where those parts which corresponded to the nine tasks described above. As a result, the task was an important unit of analysis as well. As mentioned above, the coder was "blind" to whether the driver being scored was in the FOCAL or placebo group.

Keeping with the analysis approach of Chan et al. (2008) in which researchers used the individual task as the unit of analysis, the current study examined the percentage of tasks in which at least one glance was greater than a threshold value. Analyses also focused on the average maximum glance duration in a task and the percentage of glances that were greater than a given threshold averaged across all tasks. As in Study 1, the t-test was used to assess differences. 


\subsection{Results}

The results below describe differences among the types of tasks completed by drivers. Analyses are presented for each class of tasks as well as for all tasks combined.

\subsubsection{In-Vehicle Glances: Analysis of Differences Among Task Types}

Although all the tasks in the current experiment were in-vehicle tasks, it was important to determine whether there were differences between the eye behaviors of drivers for the three vehicle/driving tasks and the six nondriving tasks. In addition, there was an a-priori distinction between the two sets of tasks that is similar to that between the in-vehicle and out-of-vehicle tasks in the Chan et al. (2008) study. For each of the nine tasks, Table 4 shows the average total time with eyes off the forward roadway, the average maximum glance from the roadway, and the average ratio of maximum glance to total time for the two training groups. Note that the ratio is the average ratio for all participants in the group and not the ratio of the averages shown in the table.

Table 4. Total Time, Maximum Glance, and Ratio of Total Time to Maximum Glance For FOCAL and Placebo Groups for Each Task.

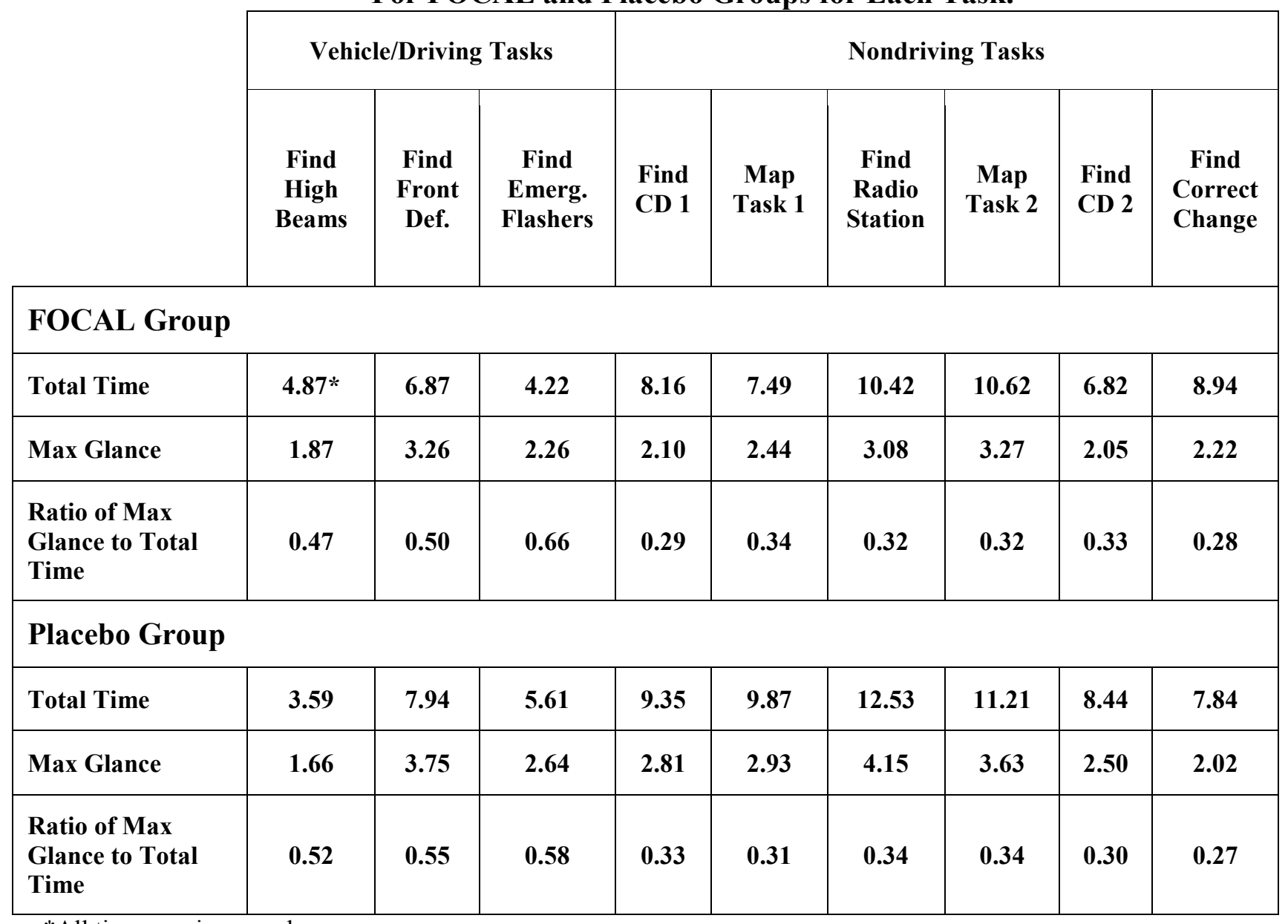

*All times are in seconds. 
Table 4 shows noticeable differences for the two classes of tasks in regards to total time with eyes off the roadway and the ratio of maximum glance to total time for a task. The table shows that drivers tended to spend less total time on the vehicle/driving tasks than the nonvehicle tasks, and that the maximum glances tended to represent a greater proportion of the overall time for the vehicle/driving tasks compared to the nondriving tasks. That is, for each training group, the ratios are generally above 0.5 for the vehicle/driving tasks, whereas it is about 0.3 for each of the other six nondriving tasks. Given the relatively short time spent on task for the vehicle/driving tasks and the higher ratio of maximum glance time to total time, it was decided to separate the task types for subsequent analyses.

\subsubsection{In-Vehicle Glances: Analysis of Effects of Training}

Results for the nondriving tasks and vehicle/driving tasks are presented separately and then combined. For the nondriving tasks, Table 5 shows that the FOCAL training produced a statistically significant effect for three of the four measures reported. The average maximum glance across tasks was over 0.5 seconds longer for the placebo training group than for the FOCAL-trained group. Perhaps more importantly, however, the FOCAL trained participants showed significantly lower average percentage of tasks in which the maximum glance was greater than 2.0 seconds, $\mathrm{t}(35)=2.28, \mathrm{p}<.05$ and 2.5 seconds, $\mathrm{t}(35)=2.27, p<.05$. The test of the differences between the FOCAL and placebo trained groups for glance greater than $3.0 \mathrm{~s}$ was not statistically significant.

Table 5. Nondriving Tasks: Maximum Glance; Percentage of Tasks in Which Maximum Glances Over $2.0 \mathrm{~s}, 2.5 \mathrm{~s}$, and $3.0 \mathrm{~s}$

\begin{tabular}{|c|c|c|c|c|}
\hline \multirow[b]{2}{*}{ Group } & \multirow{2}{*}{$\begin{array}{c}\text { Max } \\
\text { Glance } \\
\text { (seconds) }\end{array}$} & \multicolumn{3}{|c|}{$\begin{array}{c}\text { Percent of Tasks in Which } \\
\text { Maximum Glance Was } \\
\text { Greater Than }\end{array}$} \\
\hline & & $2 s$ & $2.5 \mathrm{~s}$ & $3 \mathrm{~s}$ \\
\hline FOCAL & 2.53 & $59.5 \%$ & $41.9 \%$ & $30.2 \%$ \\
\hline Placebo & 3.07 & $75.9 \%$ & $60.2 \%$ & $41.7 \%$ \\
\hline Placebo - Focal & 0.54 & $16.5 \%$ & $18.3 \%$ & $11.5 \%$ \\
\hline$t(35)$ & 2.358 & 2.279 & 2.267 & 1.456 \\
\hline $\mathbf{p}$ & 0.024 & 0.029 & 0.030 & 0.154 \\
\hline
\end{tabular}

The other measure of interest was the average percentage of glances within tasks which were greater than the three threshold values. Here, the percentages of off-road glances in each task that were greater than the threshold values were computed and averaged across the six tasks for each participant. The results in Table 6 indicated that the FOCAL trained participants had lower percentages of glances over the threshold values, although only the difference for the $2.0 \mathrm{~s}$ threshold was statistically significant $(p<0.05)$. The differences between groups for the $2.5 \mathrm{~s}$ and $3.0 \mathrm{~s}$ thresholds were not significant, although they were in the predicted direction. 
Table 6. Nondriving Tasks: Percentage of Glances Over $2.0 \mathrm{~s}, 2.5 \mathrm{~s}$, and $3.0 \mathrm{~s}$

\begin{tabular}{|c|c|c|c|}
\hline \multirow{2}{*}{ Group } & \multicolumn{3}{|c|}{ Percent of Glances } \\
\cline { 2 - 4 } & $>2.0 \mathrm{~s}$ & $>2.5 \mathrm{~s}$ & $>3.0 \mathrm{~s}$ \\
\hline FOCAL & $19.5 \%$ & $12.8 \%$ & $7.7 \%$ \\
\hline Placebo & $28.8 \%$ & $19.0 \%$ & $12.3 \%$ \\
\hline Placebo - FOCAL & $9.4 \%$ & $6.2 \%$ & $4.6 \%$ \\
\hline $\mathbf{t}(35)$ & 2.137 & 1.800 & 1.693 \\
\hline$p$ & 0.040 & 0.080 & 0.099 \\
\hline
\end{tabular}

The effect of FOCAL training on the percentage of vehicle/driving tasks in which drivers looked away at least once for more than 2.0, 2.5, and 3.0 seconds was directionally similar to the effects for the nondriving tasks, but the effects were not statistically significant (Table 7).

Table 7. Vehicle/Driving Tasks: Maximum Glance; Percentage of Tasks in Which Maximum Glances Over 2.0 s, $2.5 \mathrm{~s}$, and $3.0 \mathrm{~s}$

\begin{tabular}{|c|c|c|c|c|}
\hline \multirow[b]{2}{*}{ Group } & \multirow{2}{*}{$\begin{array}{c}\text { Max } \\
\text { Glance } \\
\text { (seconds) }\end{array}$} & \multicolumn{3}{|c|}{$\begin{array}{c}\text { Percent of Tasks in Which } \\
\text { Maximum Glance Was } \\
\text { Greater Than }\end{array}$} \\
\hline & & $2.0 \mathrm{~s}$ & $2.5 \mathrm{~s}$ & $3.0 \mathrm{~s}$ \\
\hline FOCAL & 2.42 & $59.6 \%$ & $42.1 \%$ & $24.6 \%$ \\
\hline Placebo & 2.67 & $63.9 \%$ & $54.6 \%$ & $38.9 \%$ \\
\hline Placebo - Focal & 0.538 & $4.2 \%$ & $12.5 \%$ & $14.3 \%$ \\
\hline$t(35)$ & 0.463 & 1.291 & 1.651 & 0.463 \\
\hline$p$ & 0.646 & 0.205 & 0.108 & 0.646 \\
\hline
\end{tabular}

Table 8 has the results of tests for differences between the FOCAL and placebo trained groups for performance on the vehicle/driving tasks as measured by the percentages of glances over each threshold. These tests were not statistically significant ( $p s>0.05)$. 
Table 8. Vehicle/Driving Tasks: Percentage of Glances Over $2.0 \mathrm{~s}, 2.5 \mathrm{~s}$, and $3.0 \mathrm{~s}$

\begin{tabular}{|c|c|c|c|}
\hline \multirow{2}{*}{ Group } & \multicolumn{3}{|c|}{ Percent of Glances } \\
\cline { 2 - 4 } & $>2.0 \mathrm{~s}$ & $>2.5 \mathrm{~s}$ & $>3.0 \mathrm{~s}$ \\
\hline FOCAL & 0.301 & 0.186 & 0.114 \\
\hline Placebo & 0.316 & 0.220 & 0.128 \\
\hline Placebo - FOCAL & 0.015 & 0.034 & 0.014 \\
\hline $\mathrm{t}(35)$ & 0.257 & 0.597 & 0.319 \\
\hline$p$ & 0.799 & 0.555 & 0.752 \\
\hline
\end{tabular}

When data from all nine tasks were analyzed together (see Table 9), the difference between training groups on the average maximum duration ( $2.512 \mathrm{~s}$ vs. $2.931 \mathrm{~s})$ and the difference in percentage of tasks for which the maximum glance was above the $2.5 \mathrm{~s}$ threshold $(42.8 \%$ vs. $58.1 \%)$ were both statistically significant $(p \mathrm{~s}<.05)$. The differences between training groups on the percentage of tasks for which the maximum glance was above the $2.0 \mathrm{~s}$ and $3.0 \mathrm{~s}$ thresholds were not statistically significant $(p \mathrm{~s}<.10)$.

Table 9. All Tasks Combined: Maximum Glance; Percentage of Tasks in Which Maximum Glances Over 2.0 s, $2.5 \mathrm{~s}$, and 3.0 s

\begin{tabular}{|c|c|c|c|c|}
\hline \multirow[b]{2}{*}{ Group } & \multirow{2}{*}{$\begin{array}{c}\text { Max } \\
\text { Glance } \\
\text { (seconds) }\end{array}$} & \multicolumn{3}{|c|}{$\begin{array}{l}\text { Percent of Tasks in Which } \\
\text { Maximum Glance Was } \\
\text { Greater Than }\end{array}$} \\
\hline & & $2.0 \mathrm{~s}$ & $2.5 \mathrm{~s}$ & $3.0 \mathrm{~s}$ \\
\hline FOCAL & 2.51 & $60.3 \%$ & $42.8 \%$ & $29.0 \%$ \\
\hline Placebo & 2.93 & $71.7 \%$ & $58.1 \%$ & $40.0 \%$ \\
\hline Placebo - Focal & 0.419 & $11.4 \%$ & $15.4 \%$ & $11.5 \%$ \\
\hline$t(35)$ & 2.102 & 1.765 & 2.126 & 1.719 \\
\hline$p$ & 0.043 & 0.086 & 0.041 & 0.094 \\
\hline
\end{tabular}

When data from all nine tasks were combined (see Table 10), the FOCAL trained group did not significantly differ from the placebo group in the percentages of glances over each threshold $(p s>0.05)$. 
Table 10. All Tasks Combined: Percentage of Glances Over $2.0 \mathrm{~s}, 2.5 \mathrm{~s}$, and $3.0 \mathrm{~s}$

\begin{tabular}{|c|c|c|c|}
\hline \multirow{2}{*}{ Group } & \multicolumn{3}{|c|}{ Percent of Glances } \\
\cline { 2 - 4 } & $>2.0 \mathrm{~s}$ & $>2.5 \mathrm{~s}$ & $>3.0 \mathrm{~s}$ \\
\hline FOCAL & $23.3 \%$ & $15.0 \%$ & $9.2 \%$ \\
\hline Placebo & $29.7 \%$ & $20.0 \%$ & $12.4 \%$ \\
\hline Placebo - FOCAL & $6.40 \%$ & $5.00 \%$ & $3.20 \%$ \\
\hline$t(35)$ & 1.555 & 1.437 & 1.277 \\
\hline$p$ & 0.129 & 0.16 & 0.21 \\
\hline
\end{tabular}

\subsection{Discussion}

The present study demonstrated that the FOCAL-trained participants were significantly less likely than a placebo training group to take excessively long glances away from the roadway when nondriving tasks were performed in a live driving environment. The same pattern held true for the vehicle/driving tasks, but the differences were not statistically significant. This suggests that novice drivers can be trained, in a relatively short time period, to manage their glances while performing in-vehicle tasks. It was interesting, but not surprising, to discover that the vehicle/driving tasks took on average less overall time than the nondriving tasks. This suggests that the novice drivers are picking up the driving tasks fairly quickly as they learn to drive, but tasks not related to driving are more distracting and could potentially lead to greater crash risk.

Although researchers took a number of precautions to ensure the quality of the field study (e.g., random assignment, coder blind to participant training), some issues may have had a biasing effect on the study results. Most notably, safety considerations required that a qualified driving instructor ride in the front passenger seat with the participant. The instructor's presence may have increased participants' sense of safety, which in turn may have led to an increased willingness to take in-vehicle glances relative to how the driver would normally behave during unaccompanied driving. An alternative possibility is that participants in this field study were more conservative in the presence of two mature adults during the evaluation than if they drove solo. Also, with any controlled experiment, the participants may have felt a need to attempt the tasks since they knew their task performance was being monitored. The driving instructor noted, however, that the actions and behaviors observed during the study drives were not abnormal for beginning drivers. If this instructor's anecdotal assessment is valid, then it supports the conclusion that participants were driving and performing tasks as they normally would in their day-to-day driving.

Finally, the field assessment was conducted immediately after the FOCAL training. Thus, while the results strongly suggest that FOCAL can change behavior, no information is available on how long that behavior change might last. Additional research looking at the persistence of the training effect and, ultimately, at the crash rates of FOCAL-trained drivers would be needed to complete the assessment of FOCAL as a safety countermeasure. 


\section{STUDY 3: SIMULATOR EVALUATION OF FOCAL}

The PC-based test and field test of FOCAL provided strong evidence that FOCAL was indeed affecting the behaviors of young drivers. A final step was to determine if the results could be replicated using a similar protocol in a high fidelity simulator. Should the results be replicated, it would increase the evidence of FOCAL's impact on behavior and support the usefulness of simulators in the development and testing of similar driver training programs in the future.

\subsection{Method}

The following sub-sections provide details on the study population, materials, procedures, and analyses. Where the methods and materials were the same as those used in the PC-based test and field test, shorter descriptions are provided.

\subsubsection{Participants}

Participants were recruited from Amherst and surrounding towns close to UMass. There were 40 participants in the experiment, 23 males and 17 females. All of the individuals who participated in the experiment were between 16 to 18 years old and held junior operators' licenses (restricted licenses) for less than 6 months. Twenty participants each were randomly assigned to either the FOCAL or placebo training groups. The mean age of participants in the FOCAL group was 16 years 6 months, and the mean age of participants in the placebo group was 16 years 5 months. Parental consent and participant assent was obtained. Participants were paid $\$ 50$ for participation.

\subsubsection{Materials}

Computers. The same laptops and software used for training in the field study were again used here. Laptops were placed on individual desks in the Human Performance Laboratory, and participants could not see what another participant was doing.

$\boldsymbol{A M A P}$. The AMAP used in Studies 1 and 2 was used before and after administration of the FOCAL and placebo training.

FOCAL Training. The FOCAL training used in Studies 1 and 2 was used here for the experimental training group.

Placebo Training. Placebo training consisted of the same Rules of the Road paper packet used in Studies 1 and 2.

Eye Tracker. The same eye tracker used in the field study was used here.

Simulator. The driving simulator at the Human Performance Laboratory consists of a fully equipped 1995 Saturn sedan placed in front of three screens subtending 135 degrees 
horizontally. The virtual environment was projected on each screen at a resolution of $1024 \times$ 768 pixels and at a frequency of $60 \mathrm{~Hz}$ (see www.ecs.umass.edu/hpl for a more detailed description). The participant sat in the car and operated the controls, moving through the virtual world according to his or her inputs to the car. The audio was controlled by a separate system which consisted of two mid/high frequency speakers located on the left and right sides of the car and two sub-woofers located under the hood of the car. This system provides realistic road, wind and other vehicle noises with appropriate direction, intensity, and Doppler shift.

Secondary Tasks and Task Material. The same secondary tasks and materials from the field test were used in this study. The vehicle/driving tasks included turning the headlights on high beam, activating the front window defroster, and activating the emergency flashers. The non-vehicle tasks included tuning the radio, looking for a CD in a case, trying to find a street on a map, and taking 40 cents out of a cup holder. In one instance the CD was present and in the other it was not present. Similarly, in one map task the street was present and not present in the other. For the change task, 10 coins where placed in the cup holder, but only one combination of coins added up to 40 cents (one quarter, one dime, one nickel).

Simulated Drive and Task Instructions. The driving course involved a simulated drive. The course was designed to be as similar as possible to the environment encountered by participants during the field test. The drive involved various turns as participants drove through a single lane visual database populated with vegetation and housing with randomly parked vehicles along the side of the roadway. The task calls used the same task wording as the field test except that all the tasks were called out using recorded audio files activated automatically during the simulator drive. This enabled the task to be initiated at the exact same location for the exact period of time for all participants. The participants were allotted exactly 15 seconds to perform each task. All the tasks were initiated on straight sections of the drive.

\subsubsection{Design}

The experimental design was a between subjects design with training group (FOCAL or placebo) as the between subjects variable. Glance durations away from the roadway during the simulated drive were the primary dependent variable.

\subsubsection{Procedure}

Participants completed the study at the Human Performance Laboratory at UMass. Each participant took approximately 2 hours to complete all aspects of the study. After the initial briefing about the study, the participants filled out a demographics questionnaire. In the training portion of the study, participants were given the AMAP pre-test and either the FOCAL or placebo training. After training, participants completed the AMAP post-test.

A researcher then provided the participants with brief instructions about driving the simulator. Participants were permitted a practice drive to familiarize themselves with the simulator controls. Once the practice drive was completed, the participants were fitted with a mobile eye tracker, and the experimenter performed the eye tracker calibration. After completing the calibration, the experimenter explained that the secondary tasks would involve 
tasks that were associated with control of the vehicle systems and tasks which were not in any way related to the control of the vehicle. The participants were told that the task would be requested automatically through the audio system in the simulator. Once the participant indicated that all instructions given to him or her were clear, the evaluation drive began. After the simulated drive, the participants were debriefed and any questions answered.

\subsection{Data Reduction and Analysis}

The same approach used in the field test was employed for the simulator study. The following describes these analyses again as a reminder to the reader. Various measures were computed from the driver's pattern of eye movements that were scored on a frame-by-frame basis from the eye tracker video data $(30 \mathrm{~Hz})$. The video output of the eye tracker contains crosshairs superimposed on a view of the driver's forward view, with the crosshairs representing the driver's point of gaze on the forward view. However, the primary coding was of the locations of fixations. More specifically, the fixations were coded as either being on road or off road. Audio was recorded on the eye tracking videos, allowing the scorer to hear when the participant was instructed to begin and end a secondary task. While the participant was performing the task, the scorer recorded the time stamp for the video frames each time the participant's point of gaze transitioned from either on to off road or vice versa. A transition was recorded anytime the participant's point of gaze crossed the boundary between the test vehicle's windshield and dashboard.

The primary unit of analysis was the duration of a glance rather than the duration of individual fixations. A glance is defined as a series of successive fixations that are either on road or off road. The results below focus on the duration of off-road glances as the measure of inattention to the forward roadway. In addition, the only parts of the drive that were analyzed for eye movement behavior where those parts which corresponded to the nine tasks described above. The coder was "blind" to whether the driver being scored was in the FOCAL or placebo group.

As in the analysis approach of Study 2, this study examined the percentage of tasks in which at least one glance was greater than a threshold value using the t-test. Analyses also focused on the average maximum glance duration in a task and the percentage of glances that were greater than a given threshold averaged across all tasks.

\subsection{Results}

Results mirror those presented for the field study. The introductory text to each result is the same as that found in the description for the field study.

\subsubsection{In-Vehicle Glances: Analysis of Differences Among Task Types}

Although all the tasks in the current experiment were in-vehicle tasks, it was important to determine whether there were differences between the eye behaviors of drivers for the three vehicle/driving tasks and the six nondriving tasks. In addition, there was an a-priori distinction between the two sets of tasks that is similar to that between the in-vehicle and out-of-vehicle tasks in the Chan et al. (2008) study. For each of the nine tasks, Table 11 shows the average 
total time with eyes off the forward roadway, the average maximum glance from the roadway, and the average ratio of maximum glance to total time for the two training groups. Note that the ratio is the average ratio for all participants in the group and not the ratio of the averages shown in the table.

Table 11. Total Time, Maximum Glance, and Ratio of Total Time to Maximum Glance For FOCAL and Placebo Groups for Each Task.

\begin{tabular}{|c|c|c|c|c|c|c|c|c|c|}
\hline & \multicolumn{3}{|c|}{ Vehicle/Driving Tasks } & \multicolumn{6}{|c|}{ Nondriving Tasks } \\
\hline & $\begin{array}{c}\text { Find } \\
\text { High } \\
\text { Beams }\end{array}$ & $\begin{array}{l}\text { Find } \\
\text { Front } \\
\text { Def. }\end{array}$ & $\begin{array}{c}\text { Find } \\
\text { Emerg. } \\
\text { Flashers }\end{array}$ & $\begin{array}{l}\text { Find } \\
\text { CD } 1\end{array}$ & $\begin{array}{c}\text { Map } \\
\text { Task } 1\end{array}$ & $\begin{array}{c}\text { Find } \\
\text { Radio } \\
\text { Station }\end{array}$ & $\begin{array}{c}\text { Map } \\
\text { Task 2 }\end{array}$ & $\begin{array}{l}\text { Find } \\
\text { CD } 2\end{array}$ & $\begin{array}{l}\text { Find } \\
\text { Correct } \\
\text { Change }\end{array}$ \\
\hline \multicolumn{10}{|c|}{ FOCAL Group } \\
\hline Total Time & $3.983 *$ & 11.054 & 7.967 & 7.762 & 10.271 & 11.731 & 10.056 & 7.484 & 6.928 \\
\hline Max Glance & 1.410 & 2.144 & 2.882 & 2.742 & 2.921 & 2.809 & 2.368 & 2.242 & 2.062 \\
\hline $\begin{array}{l}\text { Ratio of Max } \\
\text { Glance to Total } \\
\text { Time }\end{array}$ & 0.354 & 0.261 & 0.297 & 0.276 & 0.267 & 0.249 & 0.279 & 0.300 & 0.298 \\
\hline \multicolumn{10}{|c|}{ Placebo Group } \\
\hline Total Time & 4.806 & 12.903 & 9.240 & 9.194 & 11.722 & 12.321 & 12.647 & 10.272 & 8.525 \\
\hline Max Glance & 1.788 & 2.410 & 3.336 & 3.370 & 2.930 & 3.953 & 3.562 & 3.019 & 2.760 \\
\hline $\begin{array}{l}\text { Ratio of Max } \\
\text { Glance to Total } \\
\text { Time }\end{array}$ & 0.372 & 0.259 & 0.385 & 0.262 & 0.287 & 0.238 & 0.313 & 0.294 & 0.324 \\
\hline
\end{tabular}

*All times are in seconds.

\subsubsection{In-Vehicle Glances: Analysis of Effects of Training}

Results for the nondriving tasks and vehicle/driving tasks are presented separately and then for the tasks combined. For the six nondriving tasks, Table 12 shows that the FOCAL training produced a statistically significant $(p s<0.05)$ effect for all four measures reported. The average maximum glance across tasks was over a half a second longer for the placebo training group than for the FOCAL-trained group. Perhaps more importantly, however, the FOCAL trained participants showed significantly lower average percentage of tasks in which the maximum glance was greater than $2.0 \mathrm{~s}$ and $2.5 \mathrm{~s}$, and $3.0 \mathrm{~s}$. The test for percentage of 
nondriving tasks with maximum glances greater than 3.0 seconds approached statistical significance $(\mathrm{p}=0.050)$.

Table 12. Nondriving Tasks: Maximum Glance; Percentage of Tasks in Which Maximum Glances Over 2.0 s, $2.5 \mathrm{~s}$, and 3.0 s

\begin{tabular}{|c|c|c|c|c|}
\hline \multirow[b]{2}{*}{ Group } & \multirow{2}{*}{$\begin{array}{c}\text { Max } \\
\text { Glance } \\
\text { (seconds) }\end{array}$} & \multicolumn{3}{|c|}{$\begin{array}{c}\text { Percent of Tasks in Which } \\
\text { Maximum Glance Was } \\
\text { Greater Than }\end{array}$} \\
\hline & & $2 \mathrm{~s}$ & $2.5 \mathrm{~s}$ & $3 \mathrm{~s}$ \\
\hline FOCAL & 2.486 & $59.2 \%$ & $38.3 \%$ & $21.7 \%$ \\
\hline Placebo & 3.073 & $80.8 \%$ & $67.5 \%$ & $40.8 \%$ \\
\hline Placebo - Focal & 0.587 & $21.7 \%$ & $29.2 \%$ & $19.2 \%$ \\
\hline$t(38)$ & 2.366 & 2.679 & 3.207 & 2.02 \\
\hline$p$ & 0.023 & 0.011 & 0.003 & 0.050 \\
\hline
\end{tabular}

The other measure of interest was the average percentage of glances within tasks which were greater than the three threshold values. Here, the percentages of off-road glances in each task that were greater than the threshold values were computed and averaged across the six tasks for each participant. The results in Table 13 indicated that the FOCAL trained participants had lower percentages of glances over the threshold values. The differences for the $2.0 \mathrm{~s}$ and $2.5 \mathrm{~s}$ thresholds were statistically significant $(p s<0.05)$, and the difference approached significance $(p<0.10)$ for the $3.0 \mathrm{~s}$ threshold.

Table 13. Nondriving Tasks: Percentage of Glances Over $2.0 \mathrm{~s}, 2.5 \mathrm{~s}$, and $3.0 \mathrm{~s}$

\begin{tabular}{|c|c|c|c|}
\hline \multirow{2}{*}{ Group } & \multicolumn{3}{|c|}{ Percent of Glances } \\
\cline { 2 - 4 } & $>2.0 \mathrm{~s}$ & $>2.5 \mathrm{~s}$ & $>3.0 \mathrm{~s}$ \\
\hline FOCAL & $16.7 \%$ & $9.9 \%$ & $4.9 \%$ \\
\hline Placebo & $31.9 \%$ & $18.7 \%$ & $10.2 \%$ \\
\hline Placebo - FOCAL & $15.2 \%$ & $8.8 \%$ & $5.3 \%$ \\
\hline $\mathbf{t}(38)$ & 3.379 & 2.494 & 1.988 \\
\hline$p$ & 0.0017 & 0.0171 & 0.0541 \\
\hline
\end{tabular}

The effect of FOCAL training on the percentage of vehicle/driving tasks in which drivers looked away at least once for more than 2.0, 2.5, and 3.0 seconds was directionally similar to the effects for the nondriving tasks, and the differences among the training groups were statistically significant $(p s<0.05)$ for all four measures (Table 14). 
Table 14. Vehicle/Driving Tasks: Maximum Glance; Percentage of Tasks in Which Maximum Glances Over 2.0 s, $2.5 \mathrm{~s}$, and $3.0 \mathrm{~s}$

\begin{tabular}{|c|c|c|c|c|}
\hline \multirow[b]{2}{*}{ Group } & \multirow{2}{*}{$\begin{array}{c}\text { Max } \\
\text { Glance } \\
\text { (seconds) }\end{array}$} & \multicolumn{3}{|c|}{$\begin{array}{c}\text { Percent of Tasks in Which } \\
\text { Maximum Glance Was } \\
\text { Greater Than }\end{array}$} \\
\hline & & $2.0 \mathrm{~s}$ & $2.5 \mathrm{~s}$ & $3.0 \mathrm{~s}$ \\
\hline FOCAL & 2.206 & $41.7 \%$ & $26.7 \%$ & $18.3 \%$ \\
\hline Placebo & 2.895 & $65.0 \%$ & $61.7 \%$ & $41.7 \%$ \\
\hline Placebo - Focal & 0.689 & $23.3 \%$ & $23.3 \%$ & $23.3 \%$ \\
\hline$t(38)$ & 2.418 & 2.999 & 4.200 & 2.746 \\
\hline $\mathbf{p}$ & 0.021 & 0.005 & 0.000 & 0.009 \\
\hline
\end{tabular}

The results in Table 15 indicated that the FOCAL trained participants had lower percentages of glances over the threshold values for the vehicle/driving tasks. The differences for all three thresholds were statistically significant $(p s<0.05)$.

Table 15. Vehicle/Driving Tasks: Percent of Glances Over $2.0 \mathrm{~s}, 2.5 \mathrm{~s}$, and $3.0 \mathrm{~s}$

\begin{tabular}{|c|c|c|c|}
\hline \multirow{2}{*}{ Group } & \multicolumn{3}{|c|}{ Percent of Glances } \\
\cline { 2 - 4 } & $>2.0 \mathrm{~s}$ & $>2.5 \mathrm{~s}$ & $>3.0 \mathrm{~s}$ \\
\hline FOCAL & $14.60 \%$ & $8.70 \%$ & $3.50 \%$ \\
\hline Placebo & $28.60 \%$ & $21.90 \%$ & $16.30 \%$ \\
\hline Placebo - FOCAL & $14.00 \%$ & $13.20 \%$ & $12.70 \%$ \\
\hline $\mathbf{t}(38)$ & 3.076 & 3.158 & 3.57 \\
\hline $\mathbf{p}$ & 0.004 & 0.003 & 0.001 \\
\hline
\end{tabular}

When data from all nine tasks were analyzed together (see Table 16), the differences between training groups for average maximum glance and the percentage of tasks with a glance over the various thresholds were large and statistically significant $(p \mathrm{~s}<.05)$. Also, when data from all nine tasks were combined (see Table 17), the FOCAL trained group showed lower average percentages of glances over each threshold, and all differences were statistically significant $(p s<0.05)$. 
Table 16. All Tasks Combined: Maximum Glance; Percentage of Tasks in Which Maximum Glances Over 2.0 s, $2.5 \mathrm{~s}$, and 3.0 s

\begin{tabular}{|c|c|c|c|c|}
\hline \multirow[b]{2}{*}{ Group } & \multirow{2}{*}{$\begin{array}{c}\text { Max } \\
\text { Glance } \\
\text { (seconds) }\end{array}$} & \multicolumn{3}{|c|}{$\begin{array}{c}\text { Percent of Tasks in Which } \\
\text { Maximum Glance Was } \\
\text { Greater Than }\end{array}$} \\
\hline & & $2.0 \mathrm{~s}$ & $2.5 \mathrm{~s}$ & $3.0 \mathrm{~s}$ \\
\hline FOCAL & 2.395 & $53.5 \%$ & $34.6 \%$ & $20.6 \%$ \\
\hline Placebo & 3.014 & $78.0 \%$ & $66.5 \%$ & $41.0 \%$ \\
\hline Placebo - Focal & 0.619 & $24.5 \%$ & $31.9 \%$ & $20.4 \%$ \\
\hline$t(38)$ & 2.809 & 3.745 & 4.153 & 2.517 \\
\hline$p$ & 0.008 & 0.001 & 0.000 & 0.016 \\
\hline
\end{tabular}

Table 17. All Tasks Combined: Percent of Glances Over $2.0 \mathrm{~s}, 2.5 \mathrm{~s}$, and $3.0 \mathrm{~s}$

\begin{tabular}{|c|c|c|c|}
\hline \multirow{2}{*}{ Group } & \multicolumn{3}{|c|}{ Percent of Glances } \\
\cline { 2 - 4 } & $>2.0 \mathrm{~s}$ & $>2.5 \mathrm{~s}$ & $>3.0 \mathrm{~s}$ \\
\hline FOCAL & $16.0 \%$ & $9.5 \%$ & $4.4 \%$ \\
\hline Placebo & $30.8 \%$ & $19.8 \%$ & $12.2 \%$ \\
\hline Placebo - FOCAL & $14.8 \%$ & $10.3 \%$ & $7.8 \%$ \\
\hline $\mathrm{t}(38)$ & 3.735 & 3.129 & 3.186 \\
\hline$p$ & 0.001 & 0.003 & 0.003 \\
\hline
\end{tabular}

\subsection{Discussion and Limitations}

The results from the simulator study strongly support the notion that FOCAL altered the glance behaviors of the trained drivers. The FOCAL-trained participants had substantially fewer tasks with glances over the given thresholds and had overall lower percentages of glances over the thresholds compared to the placebo training group. While these findings suggest that young drivers can be trained to better manage their glances, it is not clear if taking shorter glances away from the roadway will in fact impact the safety of younger drivers. Further, this initial effort only assessed a "same-day" effect of the training. Thus, the existence or duration of a lasting behavioral change is also unknown.

This study did not include any driving safety measures (e.g., lane position, driving speed), and the simulated environment may have provided participants with a sense of safety since a driving error would not have any "real" adverse consequence. 


\section{DISCUSSION}

This series of studies sought to develop and test a PC-based training countermeasure that would reduce inattention to the forward roadway among young, newly licensed drivers. The first study in the sequence developed the FOCAL training program and the AMAP PC-based test to assess performance on it. Young participants were randomly assigned to FOCAL or placebo training and then completed AMAP immediately thereafter. Results showed that FOCAL trained-younger drivers performed better on AMAP than did a placebo-trained group. These results suggested that the FOCAL program was capable of improving forward attention to the roadway, at least as measured by the AMAP program.

The second study extended these findings to real-world driving by conducting a field test of FOCAL's effectiveness. Newly licensed young drivers randomly assigned to FOCAL or placebo training were tasked to perform various potentially distracting in-vehicle tasks while wearing an eye tracker to measure where they were looking and driving on the open roadway. Measures from the eye tracker data indicated that the FOCAL training reduced the young drivers' propensity to look away from the forward roadway for extended durations. This was a further indication of the potential countermeasure value of FOCAL.

The second study also produced information on some interesting behavioral patterns among novice young drivers. As part of the testing, the participants were requested to perform various in-vehicle tasks to determine their willingness to take their eyes off the forward roadway. Some of these tasks were related to the operation of the vehicle such as turning on the headlights or activating the emergency flashers. The balance of the tasks were unrelated to the operation of the vehicle such as finding a $C D$ in a case or selecting a specific amount of change from an array of coins in the cup holder. Across all participants, regardless of whether they were assigned to FOCAL or placebo training, the vehicle/driving tasks took less overall time to complete and showed lower average maximum glance times compared to the nondriving tasks. The reason for this data pattern could not be determined with the study design as implemented. The finding may indicate that young drivers are more willing to take their eyes off the roadway when attempting tasks that are not fundamentally related to driving, that the driving related tasks were simpler to complete, or something else entirely.

Study 3 repeated the Study 2 protocol in a simulator. It was of interest to see if the field study results would replicate in a simulator because of the relative ease of simulator use and its inherent safety when conducting research of this type. The results showed that, as in Study 2, the FOCAL-trained group performed better than the placebo-trained group. In fact, the difference between the two groups was even greater in the simulator than what had been observed on the road.

Interestingly, while Study 2 showed a significant effect of task type (the vehicle/driving tasks and nondriving) on the performance of both groups, there was no meaningful performance difference by task type in the simulator. The reasons for this finding are not known. It could, for example, be a true simulator effect or an artifact of the different control layouts of the 1990svintage Saturn that served as the simulator platform and the late-model Hondas used on the road. 
Other than the absence of a difference between the vehicle/driving and nondriving tasks, the results of the simulator study were highly consistent with the results from Study 2 conducted on the road. This is suggests that the type of measures examined in these studies can be captured and studied in a high-fidelity, non-motion simulated driving environment with a reasonable level of confidence.

Together, the results from these studies strongly suggest that young drivers could benefit from PC-based training that addresses attention maintenance skills. The major remaining unknown is how long the training effects persist and whether the changes in behavior observed after training are, in fact, associated with reduced crash risk. This research also suggests that computer-based and simulator-based assessments to determine if training has changed forward attention behavior are likely valid at least for predicting the existence and nature of change if not its absolute magnitude. It therefore follows that further development and evaluation of FOCALlike programs using techniques similar to the ones employed in these three studies could be beneficial. Since the current studies evaluated the immediate effects of training, a productive next step would be to examine how long such training effects persist. Future research might also assess the extent to which drivers with differing levels of driving experience (e.g., intermediate, older drivers) would benefit from similarly focused training. Ultimately, research might productively examine whether countermeasures such as FOCAL impact the driving safety of younger drivers and the trained drivers throughout their driving careers. 


\section{REFERENCES}

Beijer, D., Smiley, A. and Eizenman, M. (2004). Observed driver glance behavior at roadside advertising signs. Transportation Research Record, 1899, 96-103.

Braitman, K.A., Kirley, B. B., McCartt, A.T., and Chaudry, N.K. (2008). Crashes of novice teenage drivers: Characteristics and contributing factors. Journal of Safety Research, 39, 47-54.

Chan, E., Pradhan, A. K., Knodler, M. A, Pollatsek, A. and Fisher, D. L. (January 2008). Empirical Evaluation on a Driving Simulator of the Effect of Distractions Inside and Outside the Vehicle on Drivers' Eye Behaviors. Proceedings of the 87th Transportation Research Board Annual Meeting CD-ROM, TRB, National Research Council, Washington, D.C.

Department of Transportation. (2009). Statistics and Facts About Distracted Driving. http://www.distraction.gov/stats-and-facts/. Accessed March 21, 2010.

Fisher, D.L., Thomas, F.D., Pradhan, A.K., Pollatsek, S., Blomberg, R.D., and Reagan, I. (January 2010). Development and Evaluation of a PC-based Attention Maintenance Training Program. DOT HS 811 252. Final Report. National Highway Traffic Safety Administration.

Horrey, W. J. and Wickens, C. D. (2007). In-Vehicle Glance Duration Distributions, Tails, and Model of Crash Risk. Transportation Research Record, 2018, Transportation Research Board of the National Academies, Washington, D.C., 2007, pp. 22-28.

Klauer, S. G., Dingus, T. A., Neale, V. L., Sudweeks, J. D., \& Ramsey, D. J. (2006). The Impact of Driver Inattention On Near-Crash/Crash Risk: An Analysis Using the 100-Car Naturalistic Driving Study Data. Washington, D.C.: National Highway Traffic Safety Administration.

Lee, S. E., Olsen, E. C. B., \& Simons-Morton, B. (2006). Eyeglance Behavior of Novice Teen and Experienced Adult Drivers. Transportation Research Record, 1980, 57-64.

Lerner N., and Boyd, S. (2004). Task Report: On-Road Study of Willingness to Engage in Distracting Tasks. Report Jointly Funded Under National Highway Safety Administration (Contract DTNH22-99-D-07005, Task Order Number 7) and National Institute of Child Health and Human Development (Contract GS-23F-8144H). Westat, Rockville: MD.

McKnight, J. A., \& McKnight, S. A. (2003). Young novice drivers: Careless or clueless. Accident Analysis and Prevention, 35, 921-925.

Regan, M.A., Lee, J. D. and Young, K. (2009). Driver Distraction: Theory, Effects, and Mitigation. CRC Press, Taylor Francis Group: Boca Raton, FL. 
Smiley, A., Smahel, T. and Eizenman, M. (2004). Impact of video advertising on driver fixation patterns. Transportation Research Record, 1899, 76-83

Strayer, D.L., Drews, F.A. and Crouch, D.J. (2003). A Comparison of the Cell Phone Driver and the Drunk Driver. Human Factors, 48, 381-391.

Wallace, B. (2003). External-to-vehicle driver distraction. Transport Research Series (Transport Research Planning Group). Edinburgh: Scottish Executive Social Research.

Wang, J. S., Knipling, R. R., and Goodman, M.J. (1996). The role of driver inattention in crashes: New statistics from the 1995 crashworthiness data system. In 40th Annual Proceedings of the Association for the Advancement of Automotive Medicine, Vancouver, British Columbia.

Wikman, A., Nieminen, T., \& Summala, H. (1998). Driving experience and time-sharing during in-car tasks on roads of different width. Ergonomics, 41, 358-372. 


\section{APPENDIX A: CONTENTS OF FOCAL TRAINING AND SELECTED SCREENSHOTS}


A description of the training and data collected in each section is provided below. Text in italics explains particulars of the training. Text not in italics indicates screen shots shown to participants. The actual instructions below are shortened versions of what was given to participants. The complete set of screen shots with the detailed instructions is provided in Appendix B.

\section{Practice}

1. Practice. Practice toggling between video and map views using spacebar (brings up the map view) and enter key (brings up the video), respectively. (1 min)

2. Practice. Practice using enter key to mark 'targets' on video (signs, pedestrians, incoming vehicles). (1 min)

3. Practice. Practice searching for targets on Map. (1 min)

4. Practice. Practice doing both tasks (video + map) together (X 2). (2 min)

\section{Attention Maintenance Assessment Program - Pretest}

1. Assessment. Complete Video $1+$ Map Task 1. (1 min)

2. Assessment. Complete Video $2+$ Map Task 2. (1 min)

3. Assessment. Complete Video $3+$ Map Task 3. (1 min)

4. Assessment. Complete Video $4+$ Map Task 4. (1 min)

5. Data recorded: Video score/accuracy, Up/Down durations, map target score/accuracy.
6. $\underline{\text { Time: }} 4$ videos, 4 min.

\section{Attention Maintenance Assessment Feedback}

1. Computations. Calculate the worst performance from section II (4.2) as determined by the video with the longest glance at the map.

2. Instructions: Blank Video. During the next section, you will have an opportunity to see how well you performed on the first section when you were switching your attention between glances outside the vehicle and those inside the vehicle (i.e., those directed at the map). First, we want to play back to you one of the drives you did in Part II of the study. The computer has recorded when you were looking at the roadway and when you were looking at the map. When you were looking at the map you cannot see any of the forward roadway. This will be very evident in the video when it is replayed. This will help give you a feeling for how much information you can miss when looking away from the roadway for an extended amount of time.

2. Training: Video Replay (1-4). Play back "worst performance video" while "blacking out" the glance-down durations (obtained from user's data). (1 min) 
Training: Video Replay (1-4)

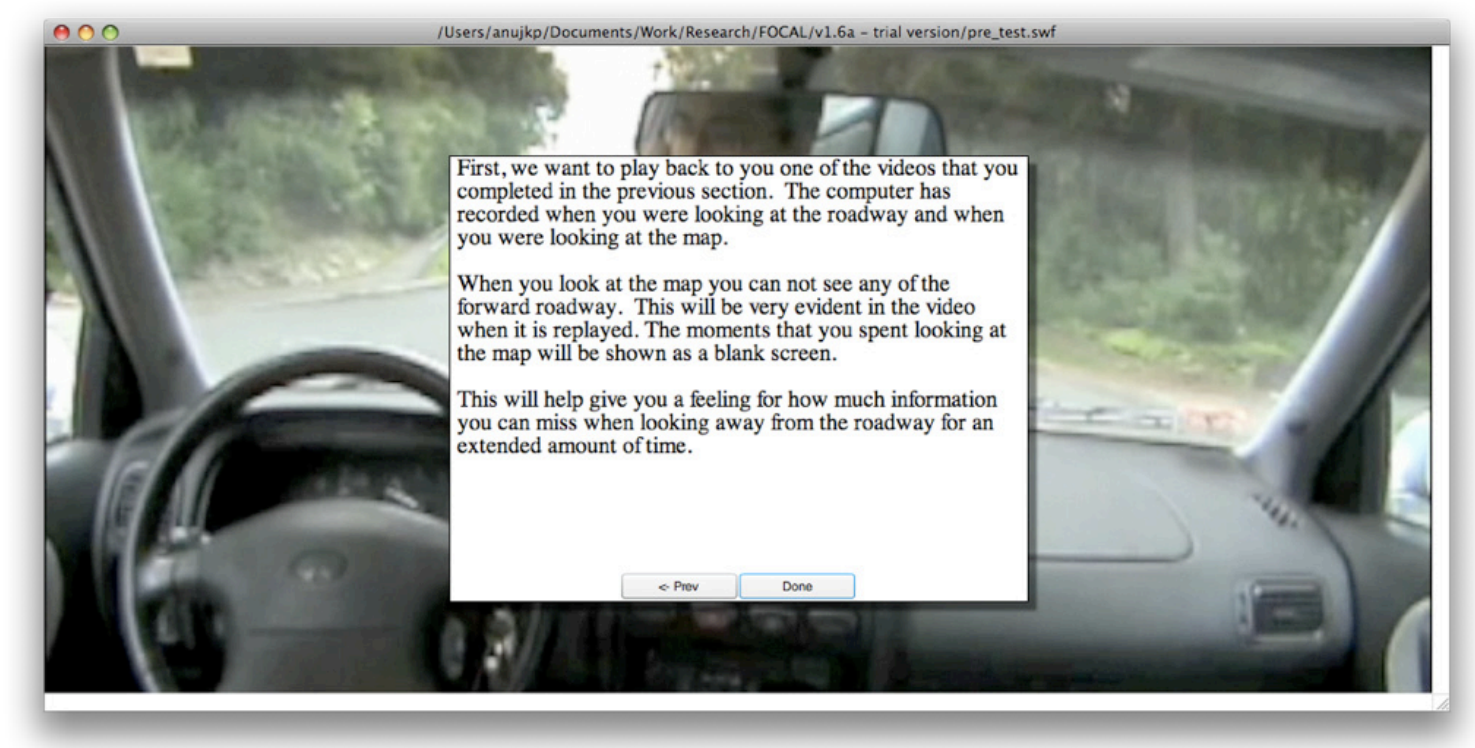

3. Feedback. As you can see, you were looking away from the forward roadway for extended periods of time during which the risk of a crash would have gone way up.

Feedback

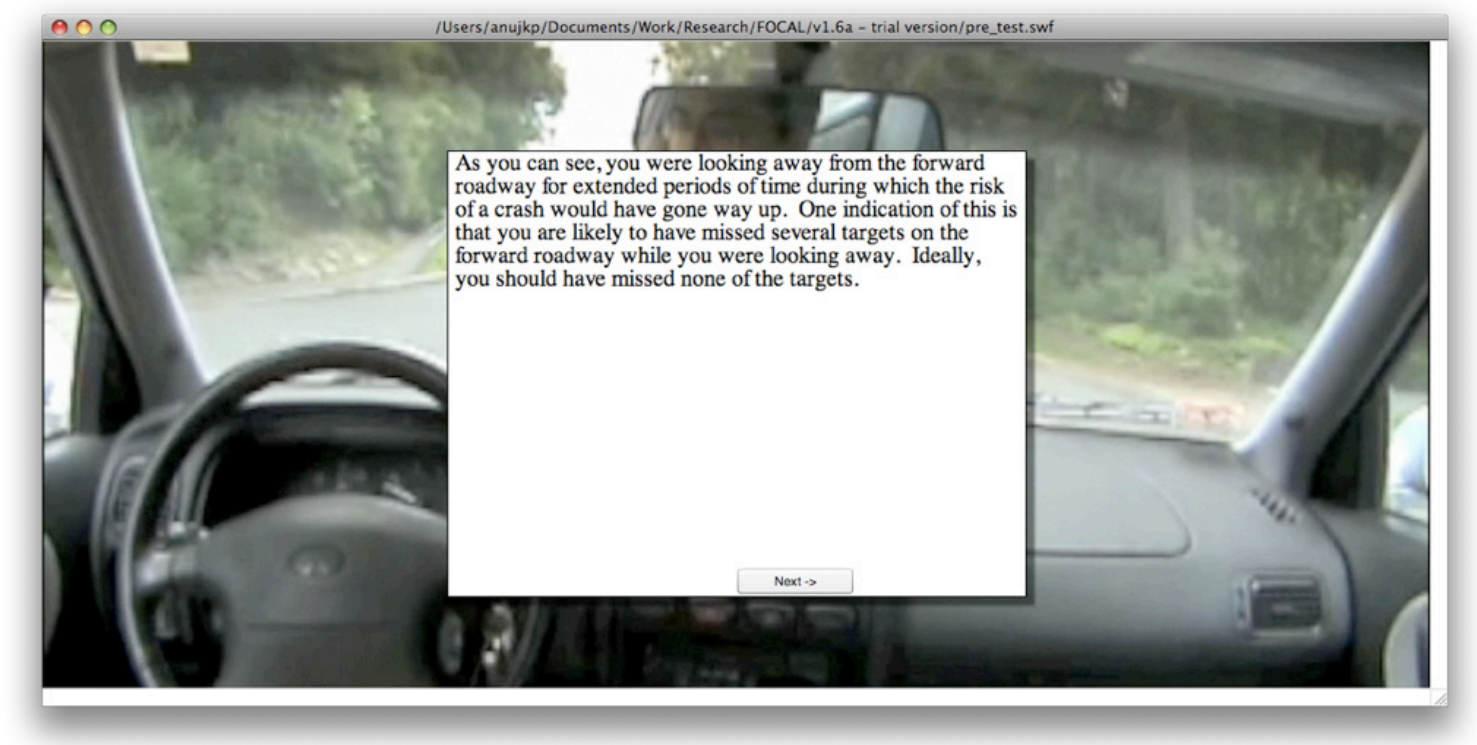

4. Instructions: Blank Video with Timer (1-4). We will now play this drive back again. In this second replay of your drive, the time you looked away will be presented on the replay so that you can start to get a feeling for how long "too long" is. Ultimately, you should learn never to look away from the road for a period more than 2 seconds to perform critical tasks such as checking the speedometer, activating the windshield wipers, and so on.

5. Training. Play back "worst performance video" while blacking out glance down durations. Also, display a countdown timer (seconds and tenths of seconds) during the black-out periods. In addition to the countdown timer, display a LARGE numeral for every second that elapses, i.e., the small countdown timer will be running normally and once the timer reaches " 1 
sec" there will be a large " 1 " that fades in and fades out on the screen, and when the timer reaches " $2 \mathrm{sec}$ " there will be a large " 2 " and so on. (1 min)

6. Feedback. How long did you look away from the forward roadway? Most teen drivers find that they looked away for longer than 2 seconds. The longer you looked away the more risk you assume. Glances longer than two seconds are associated with a crash risk three times higher than those under two seconds.

\section{Attention Maintenance Training - 3 seconds}

\section{Second Map Task - Time Controlled by System}

1. Instructions: General. We will have two sections here where we will practice performing the tasks for $3 \mathrm{sec}$ and $2.0 \mathrm{sec}$.

2. Instructions: 3 Second Map Task. In this section of the training, you will be asked to perform a dual driving and map task like the one that you just performed above. Ideally, you should do this by pulling over into a parking place and looking at the map there. However, this is not always possible without missing a critical turn, and so you may sometimes decide to compromise and look at the map when you are driving, taking only quick glances down at the map. We are going to try to train you to do this search task using such quick glances.

What is crucial to understand is that you can't look away from the roadway for very long without taking unacceptable risks. However, when you are involved in a task such as looking at a map, it is easy to get involved in the task and lose track of time. Thus, in training, we are going to try to give you something like an internal "clock" that will give you a protection against looking away from the roadway for too long.

\section{Instructions: 3 Second Map Task}

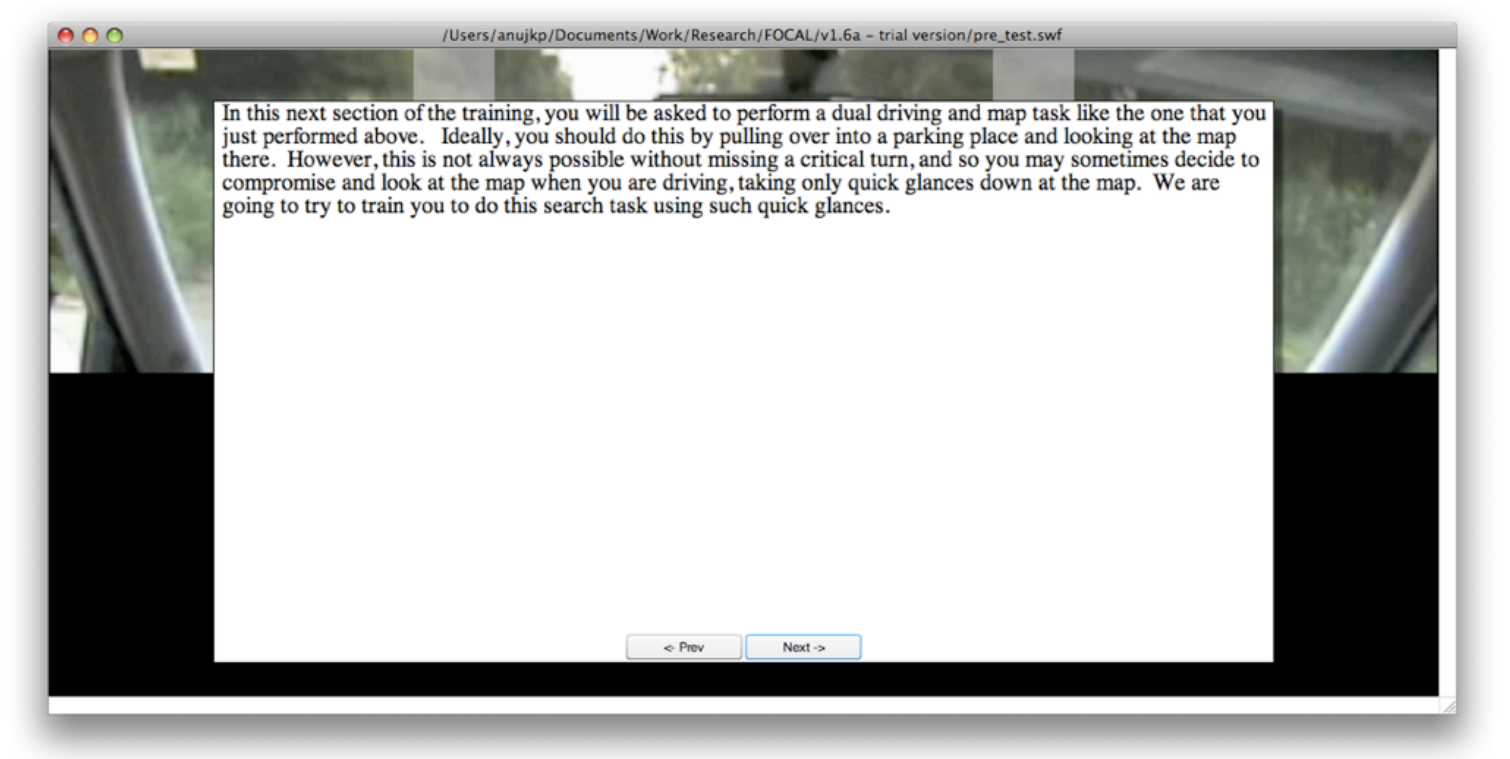

3. Instructions: Connector Street Map Task. The map task you will be doing in this section is one which you might find yourself caught having to do when you are driving. You can think of your situation as follows. You are in a city or town that you do not know well. You know the name of the street you are trying to find (the destination street) and you know it is a small side street that is not connected to the main street (origin street) on which you are driving. 
You are fairly sure that there is one street that intersects the street you are driving on that will connect up with the street you are looking for. Thus, your task is to look at the map to find the connector street that links the street you are driving on (the origin street) with the destination street towards which you are heading.

4. Practice: Example of Connector Street Map Task. An example is given in the map below. Imagine you are traveling south on Longmeadow St. heading towards Fairmont St. What street would connect you with Fairmont? You will always be shown an arrow indicating your current location and direction of travel and the four points of the compass. Your instructions on the display will appear as abbreviated directions:

\section{Connector Map Task Used in FOCAL Training}

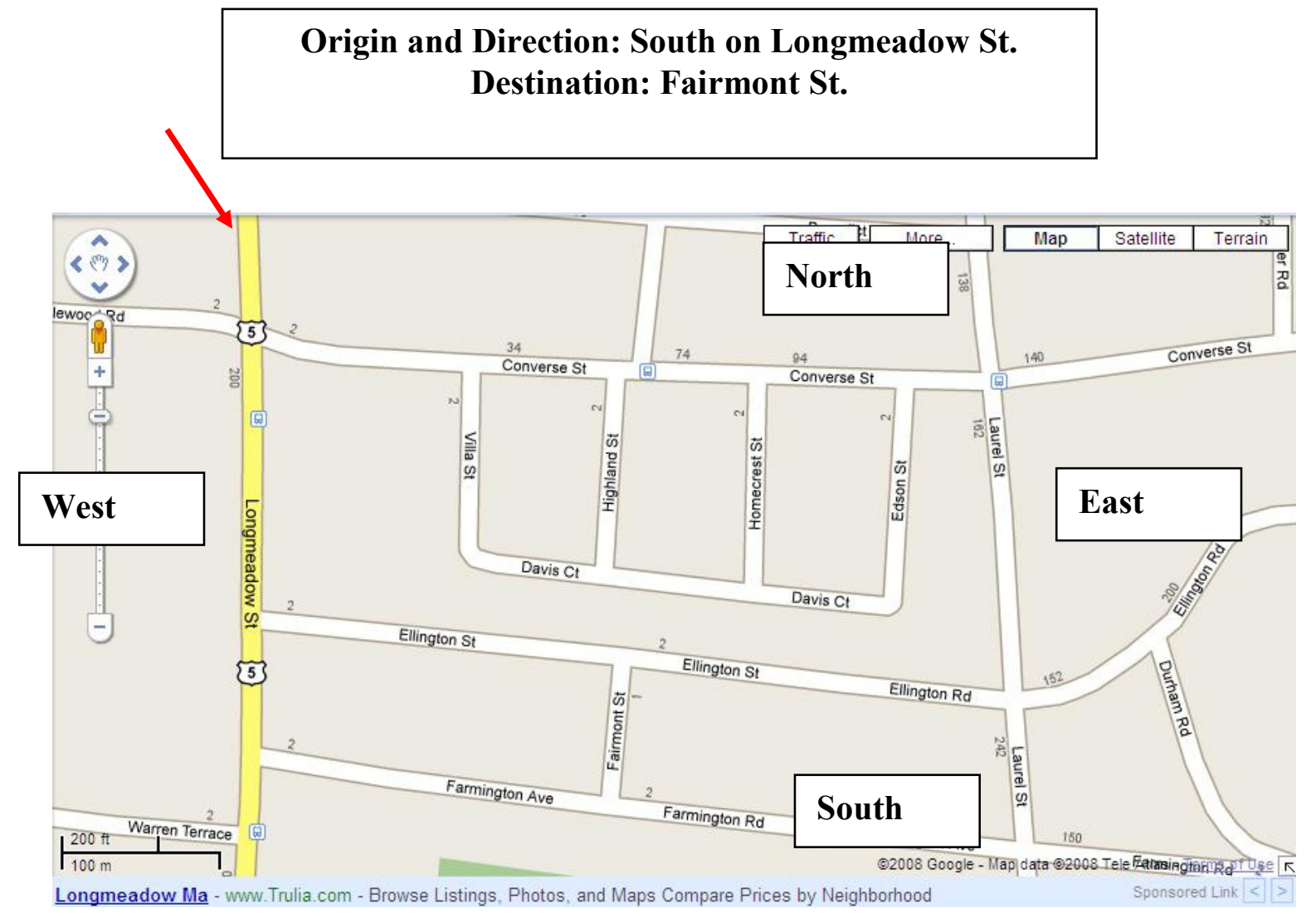

In this case, you should take Ellington St. After you see the entire video you will be given five names of streets. You must decide which street is the connector street.

5. Instructions: Procedure. Ideally, we would like to train you to get an internal "2 second alarm clock". However, we will first try for a more modest goal: making sure that glances away from the forward roadway are not longer than 3 seconds. In the first part of the training, we will insure that your glances are quick by automatically flipping the view back from the map to the roadway after 3 seconds.

If you do not get the connector street name correct, you will need to repeat the video. Again, as before, you should also respond to each time you see a significant event on the road such as a relevant sign, a pedestrian, or a vehicle in the opposing lane. If you miss any of the 
significant events you will also need to repeat the video. Remember there is no safe number of significant events that you can miss.

\section{Instruction: Procedure}

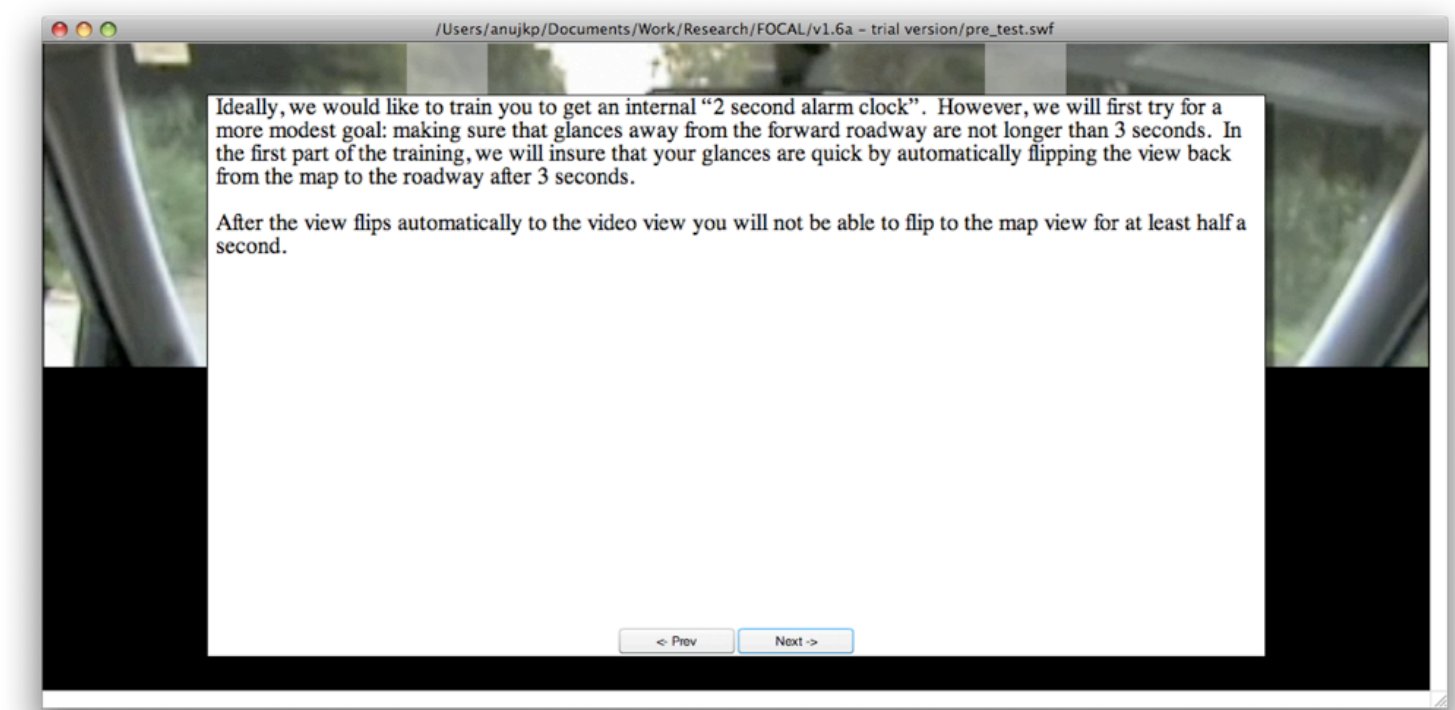

6. Training: Video 5 + Connector Map Task. (Spacebar flips to map task, but flips back automatically to video view in $3 \mathrm{sec}$. At the end of each of three videos check if user finds target. If target is not found then repeat task -- and same video -- just once. We want to provide some incentive for finding the target.)

7. Training: Video $6+$ Connector Map Task.

8. Training: Video $7+$ Connector Map Task.

9. Time. (3 videos) Min time 3 mins, Max time 6 mins.

Training: Video 5 + Connector Map Task

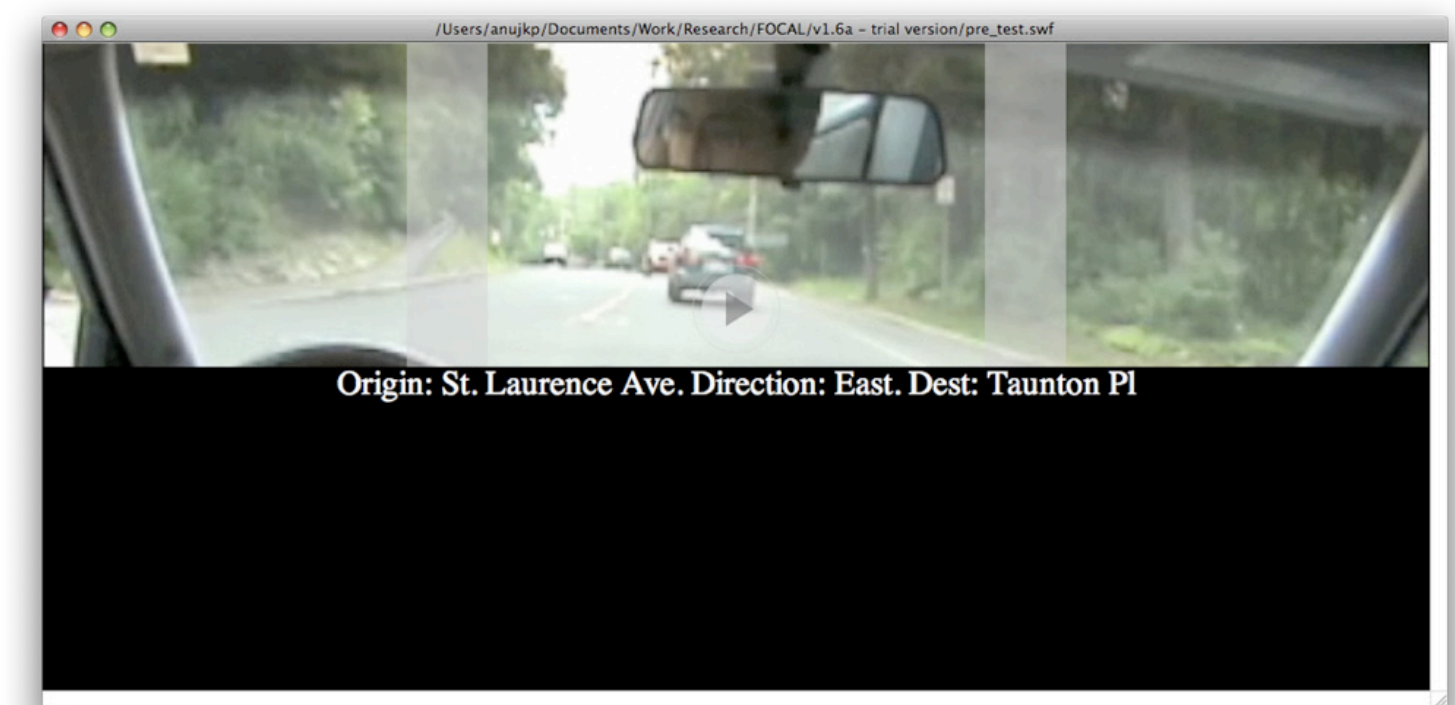




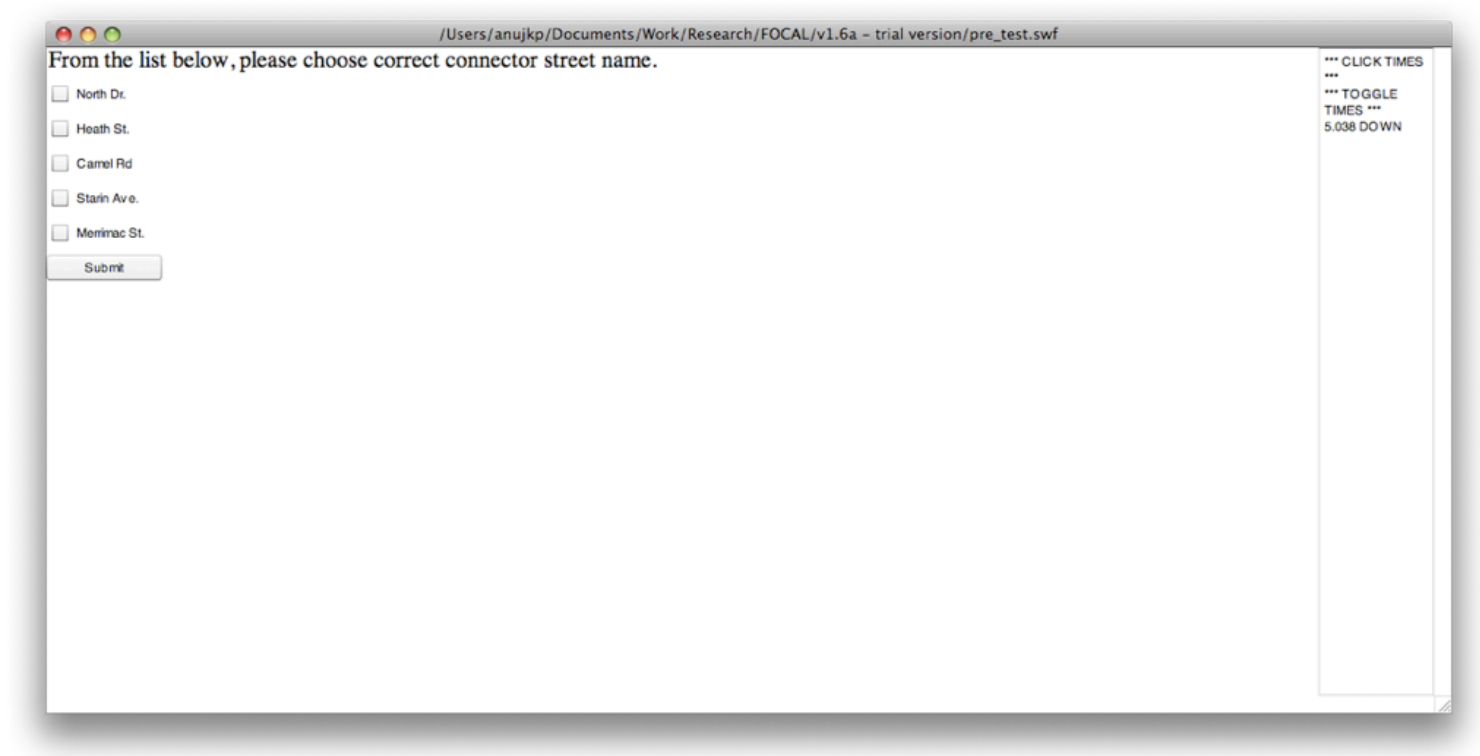

10. Feedback. Almost all students needed to repeat the task, often multiple times. Do not get discouraged.

\section{Second Map Task - Time Controlled by User, Beep Added}

1. Instructions: 3 Second Map Task - Time Controlled by User. Now you will have to time the glances yourself. You should be sure not to look at the map for more than 3 seconds in any one glance. If you do look at the map for more than 3 seconds, you will hear a beep. If you hear a beep, you'll have to practice it again. And again, if you do not get the name of the connector street correct at the end of the video or if you miss any significant events, you will also need to repeat the task.

Instructions: 3 Second Map Task - Time Controlled by User

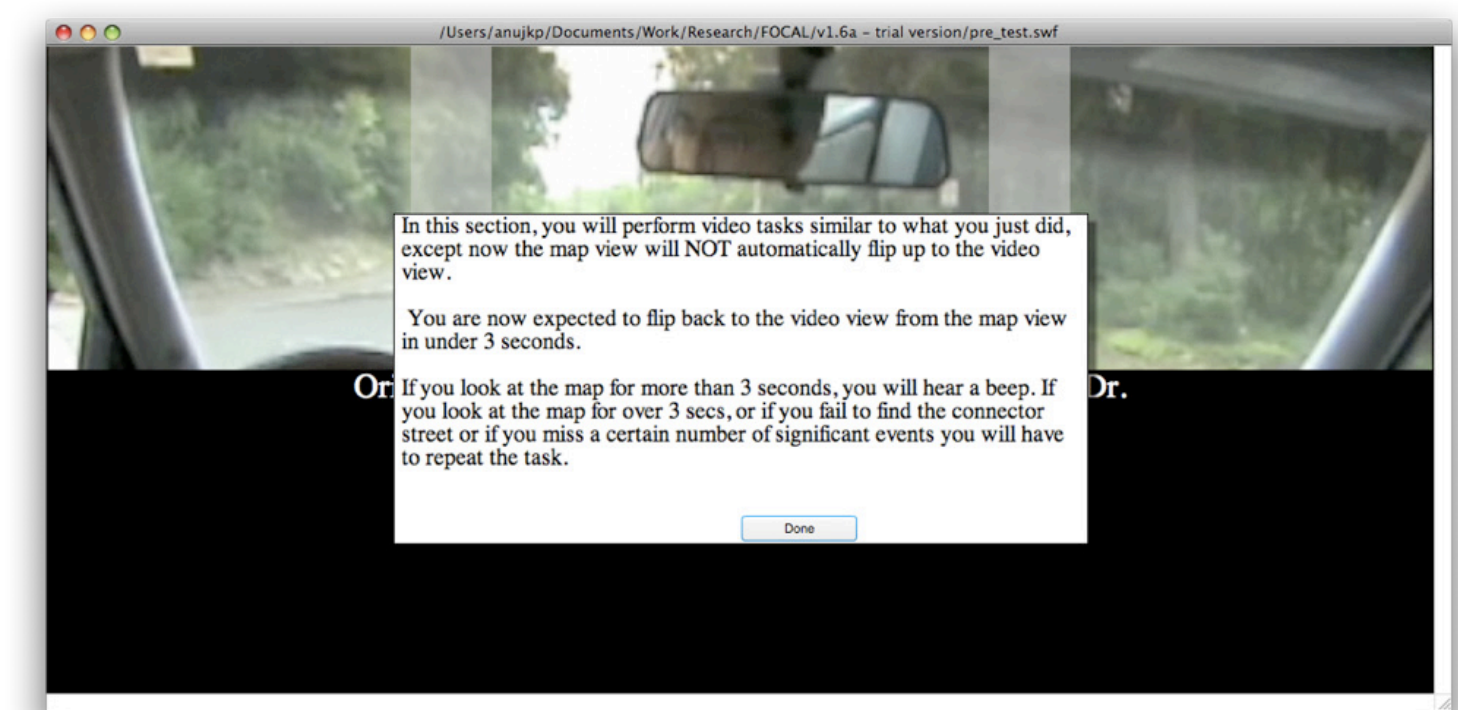


2. Training: Video $8+$ Connector Map Task. (Spacebar flips to map task; beep occurs after 3 seconds if map task not exited.)

3. Training: Video $9+$ Connector Map Task.

4. Training: Video $10+$ Connector Map Task. (Not all participants will complete this video; see comments on computations below.) video.)

5. Training: Video $11+$ Connector Map Task. (Not all participants will complete this

6. Computations. At the end of each of first two videos check to see if any of the "down" glances were over 3 seconds. If no glances were over $3 \mathrm{~s}$ in first two videos, end. If the glances were over 3 seconds in one or both of the first two videos, then repeat the task, with new video/map combination until participant gets two videos in a row with all glances less than $3 \mathrm{sec}$ or has seen four videos. In this section we are trying to get them to develop an internal clock so that they can estimate when they are looking away from the forward roadway for more than 3 sec.

6. Time. (2-4 videos) Min time 2 min, Max time 4 mins.

\section{Attention Maintenance Training $\mathbf{- 2}$ seconds}

\section{Second Map Task - Time Controlled by System}

1. General. Same as III.A and III.B except for the timing. The window here would be between 0.0 and 2.0 seconds.

2. Instructions: Training: 2 Second Map Task. We hope that you now have an internal "clock" that alerts you when more then three seconds have passed. We want this clock to alert you when only two seconds have passed. Thus, this part will be like the last part except that you should now be sure to keep your glances less than 2 seconds at a time. To begin, the program will automatically flip the view back to the roadway after 2 seconds. Again, as before, you should also respond to each time you see a significant event on the road such as a relevant sign, a pedestrian, or other vehicle. If you fail to find the connector street or you miss one or more significant events you will need to repeat the task.

2. Training: Video $12+$ Connector Map Task. (Spacebar flips to map task; beep occurs after 2 seconds if map task not exited. At the end of each of three videos check if user finds target. If target is not found then repeat task -- and same video -- just once.)

3. Training: Video $13+$ Connector Map Task.

4. Training: Video $14+$ Connector Map Task

5. Time. (3 videos) Min time 3 mins, Max time 6 mins. 
Instructions: Training: 2 Second Map Task

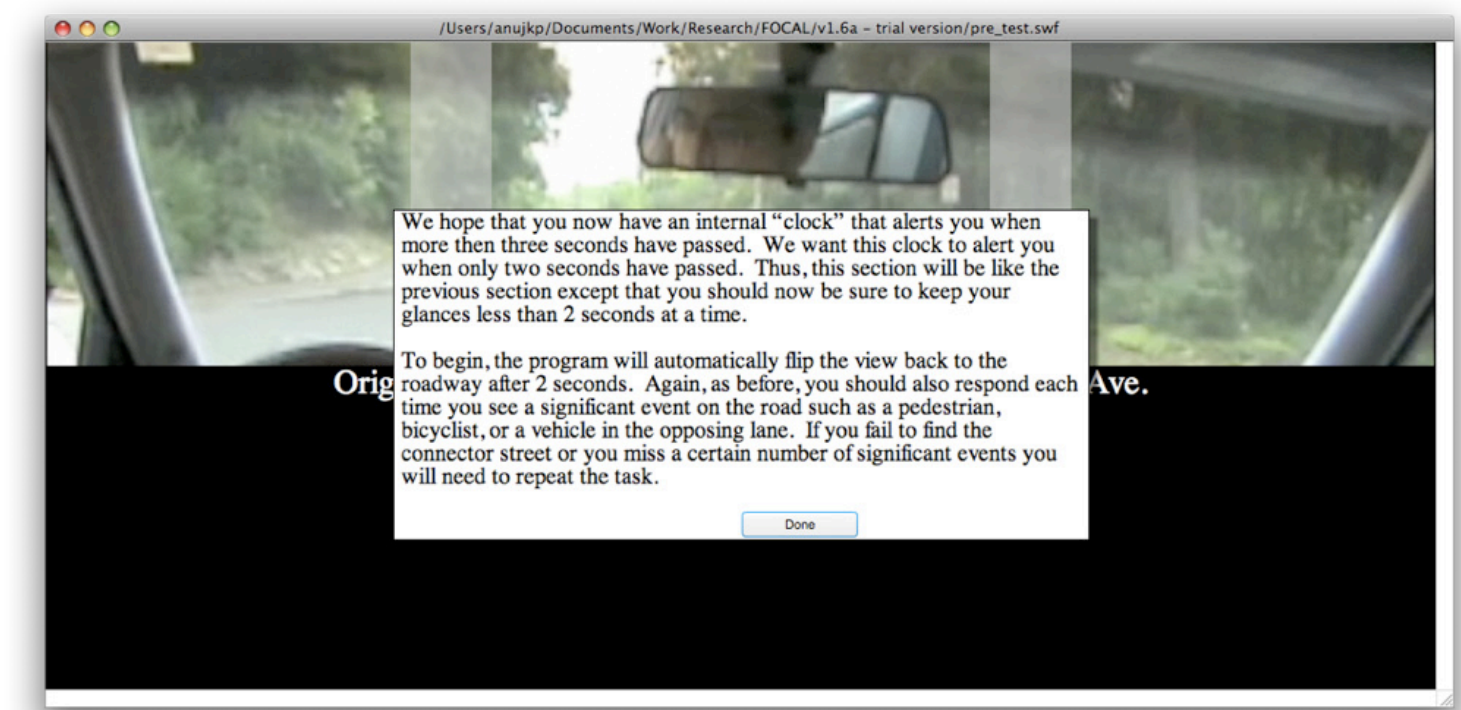

\section{Second Map Task - Time Controlled by User, Beep Added}

1. Instructions: Training: 2 Second Map Task - Time Controlled by User. Now you will have to time the glances yourself, except that you now have to make them less than 2 seconds at a time. As before, if you look at the map for more than 2 seconds, you will hear a beep, and if you hear a beep, you'll have to practice it again. Additionally, if you fail to find the connector street or miss any significant events you will have to repeat the task.

Instructions: Training: 2 Second Map Task - Time Controlled by User

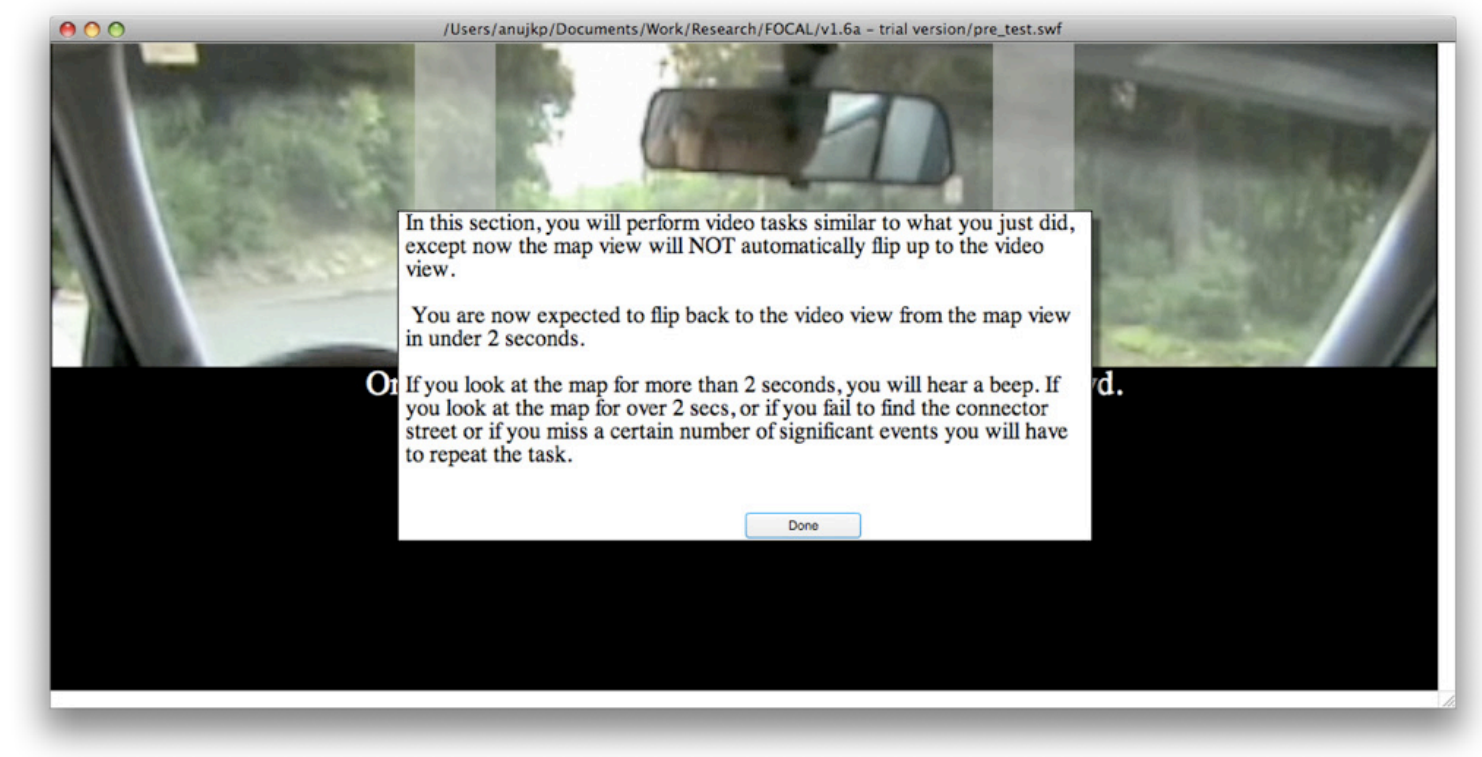

2. Training: Video 15 + Connector Map Task. (Spacebar flips to map task; beep occurs after2 seconds if map task not exited.) 
3. Training: Video $16+$ Connector Map Task.

4. Training: Video $17+$ Connector Map Task. (Not all participants will complete this video; see comments on computations below.)

5. Training: Video $18+$ Connector Map Task. (Not all participants will complete this video.)

6. Computations. At the end of each of first two videos check to see if any of the "down" glances were over 3 seconds. If no glances were over $3 \mathrm{~s}$ in first two videos, end. If the glances were over 3 seconds in one or both of the first two videos, then repeat the task, with new video/map combination until participant gets two videos in a row with all glances less than $3 \mathrm{sec}$ or has seen four videos. In this section we are trying to get them to develop an internal clock so that they can estimate when they are looking away from the forward roadway for more than 3 sec.

6. $\underline{\text { Time. }}$ (2-4 videos) Min time 2 min, Max time 4 mins.

\section{Attention Maintenance Assessment Program - Posttest}

1. Instructions. You will now get a test similar to the pre-test you took initially. As with the pre-test, your task is to report whether the street names are on the map or not. You should also respond to the significant events on the roadway as well, just as before. You should be able to schedule your glances better than before. Good luck!

2. Assessment. Complete Video $1+$ Map Task 1. (1 min)

3. Assessment. Complete Video $2+$ Map Task 2. (1 min)

4. Assessment. Complete Video $3+$ Map Task 3. (1 min)

5. Assessment. Complete Video 4 + Map Task 4. (1 min)

6. Data recorded: Video scorelaccuracy, Up/Down durations, map target scorelaccuracy.

7. $\underline{\text { Time: }} 4$ videos, $4 \mathrm{~min}$.

\section{Ending Message}

1. Exit Instructions. It is never, ever safe to take your eyes off the forward roadway. However, there may be occasions it is necessary to do such. Situations in which this could occur include ones where you need to stop suddenly and alert the vehicles behind you, perhaps by putting on your emergency flashers. Here you would need to look inside the vehicle for the button which activated the flashers. Other situations in which you might need to look away from the forward roadway include ones where an emergency vehicle is approaching, you need to get out of the way, but you cannot determine from the sound from which directing it is coming. In this case you would need to glance away from the forward roadway at the rear and side view mirrors. Also, you might be in an area which required a sudden change in speed limits. Even something as simple as monitoring your speed requires you to take your eyes away from the forward roadway. Finally, in a really rare situation you might find yourself on a highway which has no breakdown lane. You are rushing to your spouse or family member who has been taken to a hospital and is critically ill. You are not familiar with the exits, but know that the hospital is an exit off the highway on Berkeley St. You can easily locate the highway and the streets which intersect the highway on a map you have in the front seat beside you. You might in this case glance for one second every five seconds at the map in order to find the appropriate exit. 
Research indicates that if you are in a situation where you need to take your eyes away from the forward roadway, you should glance less than a total of one second during any five second interval. One way easily to remember this rule is to imagine the five fingers on your hand as each indicating one second. Only one of those fingers (i.e., your eyes) can be down during any five second interval in order to be most safe. The remaining four fingers (your eyes) must be up. 


\section{APPENDIX B: PLACEBO TRAINING}


Training $^{2}$

All travel on public roadways is controled by a system of signs, signals, pavement markings, and driving laws. No matter what type of vehicle you are driving or what kind of road you are driving on, you must obey these "rules of the road."

Please read the following five pages for a review of traffic signal and traffic sign rules.

Afterwards, please answer the open ended questions that were handed out to you. An example of a question you might be asked is the following:

Question:

If you encounter a flashing red signal, where must you stop?

\section{Answer:}

If a white stop line or crosswalk line is painted on the pavement, you must stop before the line. When there are no pavement markings you must stop as close to the intersection as needed to view traffic in both directions without entering the intersection.

Note! If you do not answer all open ended questions correctly, you will be asked to repeat the training with a new set of questions. Please be thorough reading through the material below. It should take you between 20 and 25 minutes to do such and be able to recall everything you read since you will already be familiar with much of the material.

\footnotetext{
${ }^{2}$ This training material was retrieved from the MASS RMV Driver's Manual
} 


\section{$\underline{\text { Traffic Signals }}$}

Traffic signals are lights that control the movement of vehicles and pedestrians, usually at

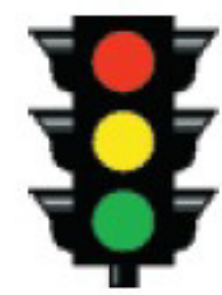
intersections. You must know what each light means and obey its signals at all times.

\section{Motor Vehicle Signals}

Traffic signals typically consist of three round lights: red, yellow, and green, from top to bottom. There are other types of signals, however, such as single flashing lights or colored arrows.

\section{Steady Red}

A steady red light means "stop." Do not go until

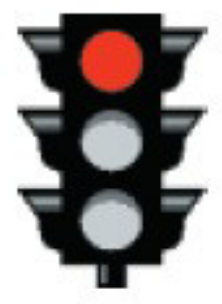
the light turns green. You may make a right turn on a red light only after coming to a complete stop, then yielding to pedestrians or other vehicles in your path. You may not turn on red if a NO TURN ON RED sign is posted.

If you are travelling on a one-way street and turning left onto another one-way street, you are allowed to turn left on a red light. Come to a complete stop and yield to pedestrians and other vehicles before turning.

\section{Steady Red Arrow}

A steady red arrow means the same as a steady red, circular signal (see the preceding Steady Red section), but a steady red arrow applies only to vehicles intending to proceed in the direction of the arrow. The same rules for "turning on red" apply.

\section{Flashing Red}

A flashing red light means the same as a STOP

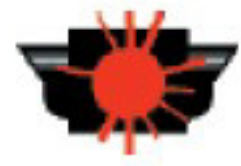
sign. Come to a complete stop. Obey the right ofway laws and proceed when it is safe to do so. If a white stop line or crosswalk line is painted on the pavement, you must stop before the line. When there are no pavement markings you must stop as close to the intersection as needed to view traffic in both directions without entering the intersection.

\section{Steady Yellow}

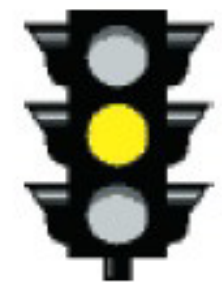

A steady yellow light means the traffic signal is changing from green to red. You must stop if it is safe to do so. If you are already stopped at an intersection or a stop line, you may not proceed. 

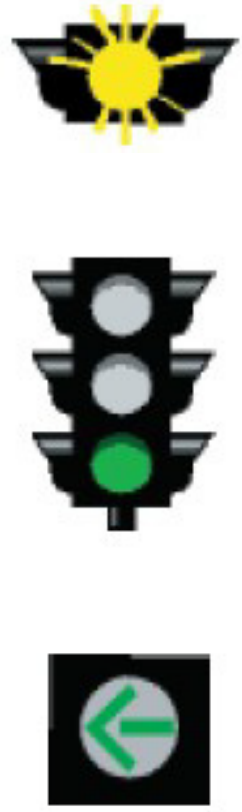

\section{LEFT ON GREEN ARROW ONLY}

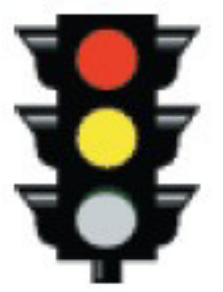

\section{Flashing Yellow}

A flashing yellow light is a warning. Proceed with caution, and stay alert. Look both ways when crossing an intersection.

\section{Steady Green}

A steady green light means "go," but only after you have yielded to other vehicles, bicycles, or pedestrians in the road. If you are crossing an intersection, make sure you have enough room to make it completely through. Never block an intersection. You may make a turn as long as you have enough space to complete the turn and avoid creating a hazard. Look out for drivers who are not obeying traffic signals or are racing through intersections.

\section{Green Arrow}

A green arrow means you may make a "protected" turn in the direction of the arrow. As long as a green arrow displays for your turning lane, pedestrians and oncoming vehicles should be stopped for red lights. Look closely for signs saying you may turn only on a green arrow.

\section{Traffic Lights Not Working}

If traffic signals are not working as they normally do, they will simply flash red or yellow lights. In these cases, follow the rules for flashing lights. If signals are blacked out and not functioning, you should be cautious and treat the intersection as having stop signs in all directions. Proceed when it is safe to do so.

\section{Traffic Signs}

Traffic signs control the flow of traffic, warn you of hazards ahead, guide you to your destination, and inform you of roadway services. The shapes and colors of traffic signs are meaningful. Sign colors mean the following:

RED—stop or prohibition

GREEN-direction, shows where you can go

YELLOW-general warning

BLACK/WHITE-regulation

BLUE-motorist service (e.g., gas, food, hotels)

BROWN-recreational, historic, or scenic site

ORANGE-construction or maintenance warning

Know signs by their appearances so you can recognize them at a distance. 


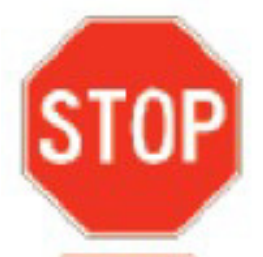

\section{4-WAY}

\section{ALL WAY}

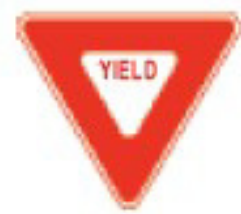

Yield

\section{Stop and Yield Signs}

The STOP sign always means "come to a complete halt" and applies to each vehicle that comes to the sign. You must stop before any crosswalk or stop line painted on the pavement. Come to a complete stop, yield to pedestrians or other vehicles, and proceed carefully. Simply slowing down is not enough. If a 4-WAY or ALL WAY sign is added to a STOP sign at an intersection, all traffic approaching the intersection must stop. The first vehicle in the intersection or four-way stop has the right of way.

When you see a YIELD sign, slow down and be prepared to stop. Let vehicles, bicyclists, and pedestrians, pass before you enter the intersection or join another roadway. You must come to a complete stop if traffic conditions require it.

\section{Regulatory Signs}

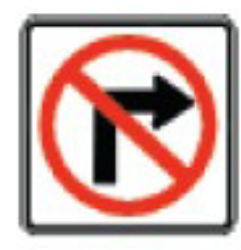

No right turn
The United States is now using an international system of traffic control signs that feature pictures and symbols rather than words. The red-and-white YIELD and DO NOT ENTER signs are examples, and you have probably seen signs that use a red circle with a diagonal slash. These signs prohibit access or movement. When you see one, think of the word no.

\section{Warning Signs}

Yellow warning signs alert you to hazards or changes in conditions ahead. The road layout may be changing, you may be approaching a school zone, or you may need to be aware of some special situation ahead. Slow down and obey the sign. 
Please review the meanings of the following traffic sign shapes.

Know traffic signs by the ir shapes

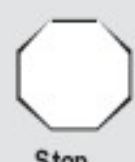

Stop

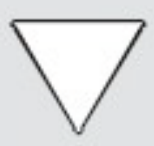

Yield

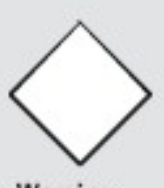

Waming

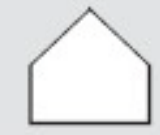

School Zone

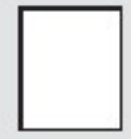

Regulation

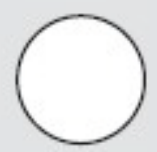

Railroad Crossing

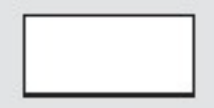

Guidellnformation

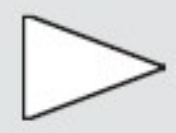

No Passing Zone

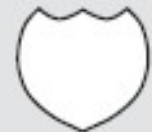

Interstate Highway 
Now, have a look at the following traffic signs (Regulatory and Warning Signs).

\begin{tabular}{|c|c|c|c|}
\hline Regulatory Traffic Signs & \\
\hline $\begin{array}{c}\text { All traffic } \\
\text { must go } \\
\text { left }\end{array}$ & $\begin{array}{c}\text { Keep to the } \\
\text { right of the } \\
\text { upcoming } \\
\text { median or } \\
\text { lane divider }\end{array}$ & pedestrians & $\begin{array}{c}\text { No parking } \\
\text { allowed } \\
\text { between } \\
\text { posted hours }\end{array}$ \\
\hline No right turn
\end{tabular}

$\mid$ Warning Signs




Lane merging
from right,
other traffic




\section{Short-Quiz:}

Participant Number:

\section{Questions:}

Please answer every question as completely as possible.

\section{1) WHAT DOES A FLASHING RED TRAFFIC LIGHT MEAN?}

A flashing red light means the same as a STOP sign: a) come to a complete stop; b) obey the right-of-way laws, and c) proceed when it is safe to do so

\section{2) WHAT IS THE PRIMARY COLOR OF HISTORIC SIGNS?}

Brown

\section{3) WHAT SHOULD YOU DO IF A SIGNAL LIGHT IS BLACKED OUT AND NOT FUNCTIONING?}

If signals are blacked out and not functioning, you should be cautious and treat the intersection as having stop signs in all directions. Proceed when it is safe to do so.

\section{4) WHAT DOES AN ORANGE TRAFFIC SIGN MEAN?}

Such a sign warns drivers of construction or maintenance.

5) WHAT DOES THE FOLLOWING TRAFFIC SIGN MEAN?

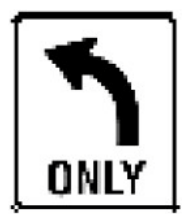

All traffic must go to the left.

6) WHAT IS THE COMMON SHAPE FOR A WARNING SIGN? 


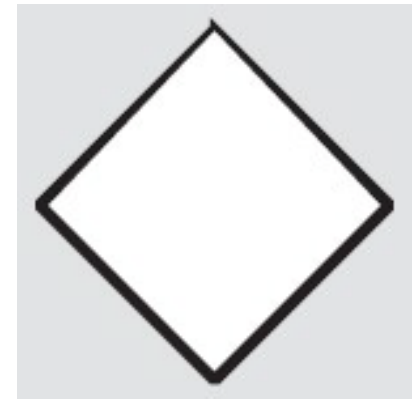

7) WHAT IS THE SHAPE OF A SIGN THAT INDICATES NO PASSING IS ALLOWED?

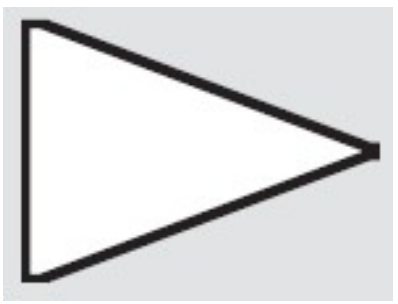

8) WHEN CAN YOU NOT TAKE A LEFT ON A STEADY GREEN EVEN THOUGH NO OTHER TRAFFIC OR PEDESTRIANS ARE IN SIGHT?

One cannot take a left on a steady green when there a sign is present indicating a left turn on a green arrow only.

9) WHAT DOES THE FOLLOWING SIGN INDICATE?

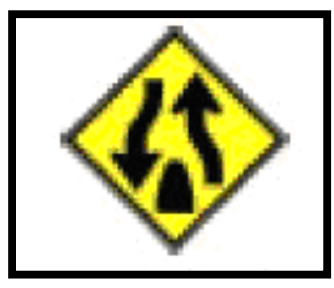

Divided highway ends

10) WHEN CAN YOU GO LEFT ON A RED LIGHT AFTER STOPPING?

When you are on a one way street. 


\section{Questions:}

Please answer every question as completely as possible.

\section{1) WHAT DOES A FLASHING YELLOW TRAFFIC LIGHT MEAN?}

A flashing yellow light is a warning. Proceed with caution, and stay alert. Look both ways when crossing an intersection.

\section{2) WHAT KIND OF SIGN IS PRIMARILY BLUE?}

Motorist service signs (e.g., gas, food, hotels).

\section{3) WHAT RULES APPLY FOR A STEADY RED ARROW?}

A steady red arrow means the same as a steady red, circular signal, but a steady red arrow applies only to vehicles intending to proceed in the direction of the arrow. The same rules for "turning on red" apply.

\section{4) WHAT DOES A GREEN TRAFFIC SIGN MEAN?}

Such a sign gives drivers direction, shows where they can go.

\section{5) WHAT DOES THE FOLLOWING TRAFFIC SIGN MEAN?}

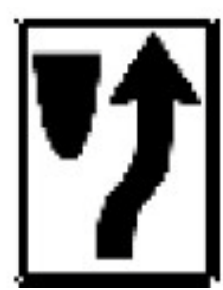

Keep to the right of the upcoming lane or median divider.

\section{6) WHAT IS THE CORRECT PROCEDURE FOR A YIELD SIGN?}

Slow down and be prepared to stop. Let vehicles, bicyclists, and pedestrians, pass before entering the intersection or joining another roadway. Come to a complete stop if traffic conditions require it.

\section{7) WHAT IS THE SHAPE OF A SIGN THAT INDICATES A RAILROAD CROSSING?}




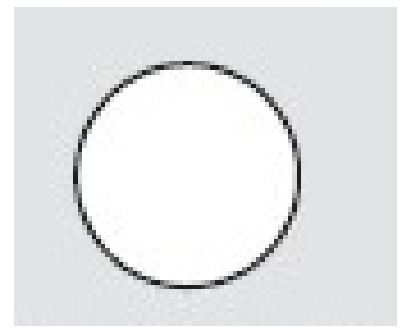

\section{8) WHO HAS THE RIGHT OF WAY AT A FOUR WAY INTERSECTION?}

The first vehicle in the intersection or four-way stop has the right of way.

19) WHAT DOES THE FOLLOWING SIGN INDICATE?

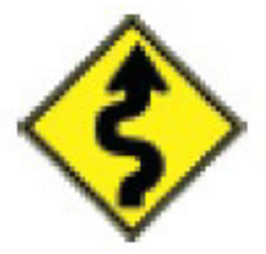

Winding road, do not pass.

\section{0) IF THERE ARE NO STOP LINES PAINTED ON THE STREET, WHERE SHOULD YOU STOP?}

When there are no pavement markings, you must stop as close to the intersection as needed to view traffic in both directions without entering the intersection. 

DOT HS 811469

July 2011 